\title{
Aerosol Therapy in Pulmonary Critical Care
}

\author{
Arzu Ari PhD RRT PT CPFT FAARC
}

\author{
Introduction \\ Aerosol Devices \\ Nebulizers \\ Pressurized Metered-Dose Inhalers \\ Spacers/Adapters \\ Delivery Efficiency of Aerosol Devices Used in Pulmonary Critical Care \\ Effect of Particle Size \\ Effect of Drug Formulation \\ Factors Affecting the Performance of Aerosol Devices \\ Factors Affecting Aerosol Drug Delivery to Ventilator-Dependent Patients \\ Factors Affecting Aerosol Delivery in Spontaneously Breathing Patients \\ With Artificial Airways \\ Effect of Disease State and Severity \\ Device Selection \\ Goal of Therapy \\ Availability of Drug and Dosage \\ Cost of Device and Dosing \\ Precision and Consistency of Dosing \\ Efficiency of the Device \\ Risks to Patients and Providers \\ Preference of Clinicians \\ Optimum Technique \\ Unmet Needs of Aerosol Medicine in Pulmonary Critical Care \\ Drug Development \\ Research on Clinical Outcomes \\ Standards of Practice \\ Summary
}

Aerosolized medications are routinely used for the treatment of critically ill patients. This paper reviews aerosol delivery devices with a focus on issues related to their performance in pulmonary critical care. Factors affecting aerosol drug delivery to mechanically ventilated adults and spontaneously breathing patients with artificial airways are reviewed. Device selection, optimum device technique, and unmet medical needs of aerosol medicine in pulmonary critical care are also discussed. Key words: aerosols; nebulizers; metered-dose inhalers; drug delivery; mechanical ventilation; artificial airways; endotracheal tube; tracheostomy tube; spacers. [Respir Care 2015;60(6):858-879. (C) 2015 Daedalus Enterprises] 


\section{Introduction}

Aerosol therapy is routinely used in pulmonary critical care. Although patients in ICUs are usually ventilatordependent, patients receiving noninvasive ventilation and spontaneously breathing patients with artificial airways are also treated in critical care. The success of delivery of aerosolized medications to critically ill patients is dependent upon the type of aerosol device and the technique used during therapy, as well as factors affecting delivery efficiency of aerosol devices. This paper reviews aerosol delivery devices with a focus on issues related to the performance of each device used in critical care. Factors affecting aerosol drug delivery to mechanically ventilated adults and spontaneously breathing patients with artificial airways are reviewed. Device selection, optimum device technique, and unmet medical needs of aerosol medicine in critical care are also discussed. Aerosol drug delivery during noninvasive ventilation is not covered here because this is being reviewed in a separate paper in this issue of Respiratory CARE.

\section{Aerosol Devices}

Aerosol devices used in pulmonary critical care can be categorized as nebulizers and pressurized metereddose inhalers (pMDIs). Nebulizers used for the treatment of critically ill patients can be divided into 3 categories: jet, ultrasonic, and mesh. Table 1 lists the characteristics of the aerosol devices used in critical care.

\section{Nebulizers}

Jet nebulizers convert liquids into aerosols that can be inhaled by patients into the lungs. They are pneumatic and incorporate baffles into their design to produce aerosols, whereas mesh and ultrasonic nebulizers use electricity to convert liquid into respirable aerosols. Using pressurized gas, the liquid solution or suspension in the cup of a jet nebulizer is

Dr Ari is affiliated with the Division of Respiratory Therapy, Georgia State University, Atlanta, Georgia.

Dr Ari presented a version of this paper at the 53rd RESPIRATORY CARE Journal Conference, "Aerosol Drug Delivery in Respiratory Care," held June 6-7, 2014, in St Petersburg, Florida.

Dr Ari has disclosed a relationship with Aerogen.

Correspondence: Arzu Ari PhD RRT PT CPFT FAARC, Division of Respiratory Therapy, Georgia State University, PO Box 4019, Atlanta, GA 30302-4019. E-mail: arzuari@ hotmail.com.

DOI: $10.4187 /$ respcare 03790 entrained into the gas stream and sheared into a liquid stream that is unstable and breaks into droplets due to surface tension. ${ }^{1-7}$ Baffles in the aerosol stream of jet nebulizers redirect the formulation back to the nebulizer cup to produce smaller particles. Liquid in the cup of the jet nebulizer cools during aerosol therapy and becomes concentrated due to evaporative loss within the nebulizer. Aerosol output and particle size thus vary directly with the temperature of the solution. ${ }^{8,9}$

Ultrasonic nebulizers use a piezoelectric transducer that produces ultrasonic waves that pass through the liquid medication in the nebulizer cup and generate aerosols at the surface of the solution. Aerosol particles are then delivered to the patient either through a fan in the ultrasonic nebulizer or by the inspiratory flow of the patient. The frequency of ultrasonic waves is inversely related to the particle size of aerosols produced by ultrasonic nebulizers, whereas the amplitude of crystal vibration is directly related to drug output delivered by the nebulizer. ${ }^{10,11}$ Several factors affect output from ultrasonic nebulizers: the characteristics of the liquid solution (viscosity, density, surface tension, and vapor pressure), the piezoelectric transducer (vibration frequency, vibration amplitude, and transducer configuration), the medication chamber (size and baffles), coupling of the medication chamber to the transducer, and flow from fans used with ultrasonic nebulizers. Ultrasonic nebulizers are not efficient in nebulizing suspensions. ${ }^{12}$ Just like jet nebulizers, the concentration of solutions increases during aerosol therapy via ultrasonic nebulizers. However, unlike jet nebulizers, they increase the solution temperature up to $15^{\circ} \mathrm{C}$ after $10 \mathrm{~min}$ of nebulization. ${ }^{8,13}$ Although small ultrasonic nebulizers are available for use in ventilator-dependent patients, the cost and size of ultrasonic nebulizers and their inefficiency in nebulizing suspensions make them undesirable for aerosol therapy in critical care. ${ }^{14}$

Mesh nebulizers can be divided into 2 categories: active and passive (static). Although active mesh nebulizers have a vibrating mesh with multiple apertures, passive (static) mesh nebulizers use a vibrating horn to generate aerosols. ${ }^{15-17}$ Active mesh nebulizers with a vibrating mesh contract and expand a vibrational element, moving a domed aperture plate with $>1,000$ tapered holes that are larger on the liquid side and smaller on the side that the droplets emerge. The drug is placed in the reservoir of the nebulizer, which is above the aperture plate. Particle size and aerosol flow are determined by the exit diameter of the holes on the aperture plate. Passive mesh nebulizers with a vibrating horn system use a piezoelectric crystal that vibrates a transducer horn interacting with the liquid formulation and a static aperture plate, pushing fluid through the mesh. Previous research has shown that the mesh nebulizer is superior to the jet nebulizer in aerosol drug delivery due to the small residual drug volume and ability to operate without adding gas to the circuit. ${ }^{18-20}$ Mesh nebulizers have very low residual volume, fast treatment time, and 
Table 1. Characteristics of Aerosol Devices Used in Critical Care

\begin{tabular}{|c|c|c|c|c|}
\hline Feature & Jet Nebulizers & Ultrasonic Nebulizers & Mesh Nebulizers & pMDIs \\
\hline Power source & Compressed gas or electrical mains & Electrical mains & Batteries or electrical mains & NA \\
\hline Portability & Restricted & Restricted & Portable & Portable \\
\hline Noise level & Noisy & Quiet & Quiet & Quiet \\
\hline Aerosol temperature & Low & High & Ambient & Ambient \\
\hline Residual volume (mL) & $0.8-2.0$ & $0.8-1.2$ & $<0.2$ & NA \\
\hline Performance variability & High & Low & Low & Low \\
\hline Drug preparation & Needed & Needed & Needed & Not needed \\
\hline Emitted dose & High & High & High & Low \\
\hline Combination of therapies & Possible if drugs are compatible & Possible if drugs are compatible & Possible if drugs are compatible & Impossible \\
\hline Treatment time & Long & Intermediate & Short & Short \\
\hline Output rate & Low & High & High & High \\
\hline Contamination & Common & Common & Less common & Impossible \\
\hline Device cost & Very low & High & High & Medium \\
\hline
\end{tabular}

the ability to nebulize a variety of solutions and suspensions. Aerosol delivery can be optimized with adjustment of the size of the pore in the mesh, the aerosol chamber, the reservoir, and the output rate of mesh nebulizers. However, like jet and ultrasonic nebulizers, these nebulizers have some disadvantages. For example, the pores of the nebulizer can become clogged with some suspensions or viscous drugs, and it may be difficult to determine this from the output of the device. Although the cost of mesh nebulizers is similar to that of ultrasonic nebulizers, they are both much more expensive than jet nebulizers. However, expensive aerosol devices such as mesh nebulizers may be more cost-effective over time. Differences in delivery efficiency between mesh and jet nebulizers may be $>3$-fold; therefore, drug doses may need to be adjusted to eliminate adverse effects that may occur due to overdose.

\section{Pressurized Metered-Dose Inhalers}

pMDIs are small, portable, convenient, multi-dose devices that use a propellant under pressure to deliver a metered dose of an aerosol through an atomization nozzle. There are several components of pMDIs, including the canister, propellant, drug formulation, metering valve, and actuator. The pMDI canister is made of aluminum, which helps prevent adhesion of drug particles and chemical degradation of drugs through a coating on the canister's inner surface. A pressurized mixture in the canister includes propellants (chlorofluorocarbon [CFC] or hydrofluoroalkane [HFA]), preservatives, flavoring agents, and active drugs. Although most pMDIs used CFC propellants, CFC pMDIs have been phased out in the United States, and newer-generation pMDIs include HFA propellants. ${ }^{21,22}$ The formulations of pMDIs can be solutions or suspensions. ${ }^{23}$

\section{Spacers/Adapters}

Because pMDIs are not designed for delivery of inhaled medications to critically ill patients who are ventilatordependent, spacer/adapters have been developed after substantial innovation and experimentation. Spacers/adapters are add-on devices that allow a pMDI to be used in a closed pressurized circuit during mechanical ventilation. ${ }^{24-26}$ The types of spacers/adapters that are used in critical care can be divided into 3 categories: unidirectional adapters, bidirectional adapters, and chamber spacers. Unidirectional adapters direct the aerosol plume in one direction, whereas bidirectional adapters release the aerosol in 2 opposite directions. Chamber spacers vary in volume from 50 to $150 \mathrm{~mL}$. They are larger than unidirectional and bidirectional adapters. Figure 1 shows commercially available spacers that are used to connect pMDI canisters in the ventilator circuit. ${ }^{27}$

\section{Delivery Efficiency of Aerosol Devices in Pulmonary Critical Care}

In the past, administration of aerosolized medications in critical care has been associated with relatively low delivery efficiency and high intra- and inter-patient variability. In 1985, MacIntyre et al ${ }^{28}$ published an important study showing that pulmonary deposition of a radiolabeled aerosol in ventilatordependent subjects was much lower than in ambulatory subjects. Later, Fuller et al ${ }^{29}$ confirmed that the efficiency of aerosol delivery with both pMDIs and nebulizers was lower in ventilator-dependent subjects than in ambulatory subjects. However, the delivery efficiency of aerosol devices in critical care has significantly improved over the years due to greater understanding of the scientific basis of aerosol therapy in 

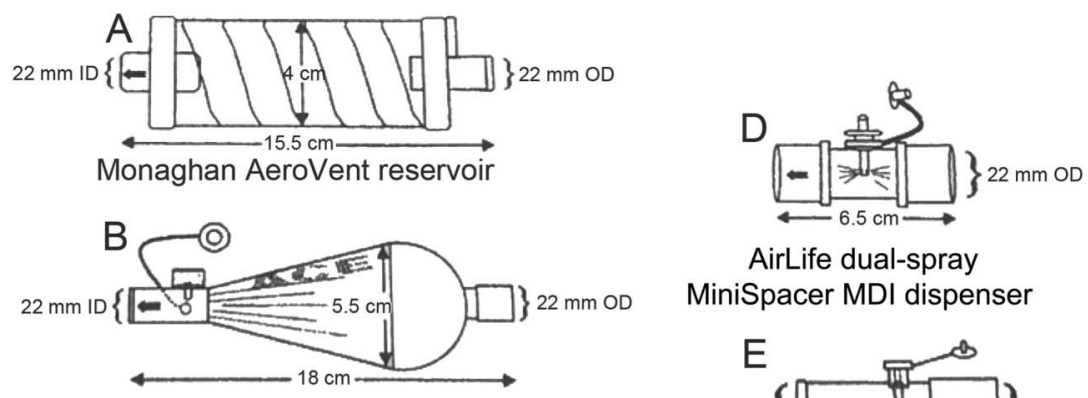

AirLife dual-spray

MiniSpacer MDI dispenser

DHD ACE reservoir
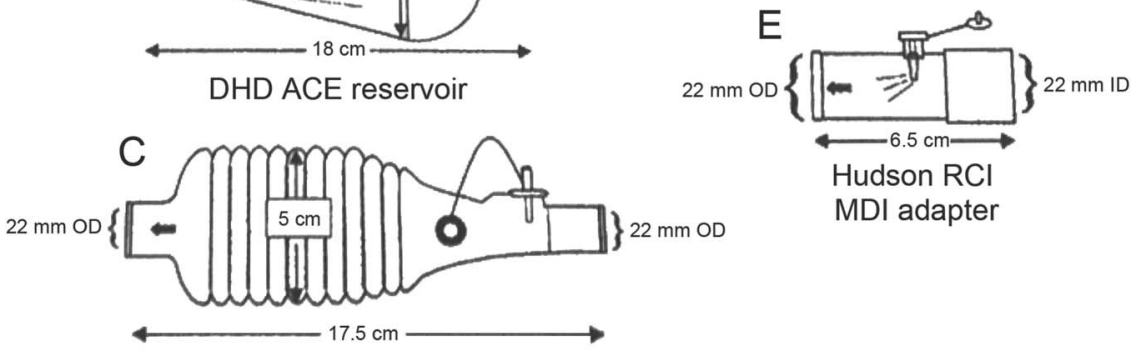

MDI adapter

AirLife MediSpacer chamber

Fig. 1. Commercially available spacers that are used to connect pressurized metered-dose inhaler canisters in the ventilator circuit. $\mathrm{ID}=$ inner diameter; $\mathrm{OD}=$ outer diameter; $\mathrm{DHD}=$ Diemolding Healthcare Division; $\mathrm{MDI}=$ metered-dose inhaler. From Reference 27.

critically ill patients, increased knowledge about optimum techniques for aerosolized medication delivery, and development of newer and more efficient aerosol devices. Previous research showed that the efficiency of pMDIs ranged from 0.3 to $97.5 \%$ 19,30-37 compared with $0-42 \%$ for nebulizers. ${ }^{14,18,19,32,34,38-42}$ There are significant differences in the delivery efficiency of aerosol devices due to many factors, which can be divided into 6 categories: (1) effect of particle size, (2) effect of drug formulations, (3) factors affecting aerosol device performance, (4) factors affecting aerosol drug delivery to ventilator-dependent patients, (5) factors affecting aerosol delivery to spontaneously breathing patients with artificial airways, and (6) effect of disease state and severity.

\section{Effect of Particle Size}

The size of an aerosol particle has a major impact on aerosol deposition in critically ill patients. It is known that a higher proportion of aerosol particles in a respirable fraction of 1-5 $\mu \mathrm{m}$ are deposited in the lung. Large particles generated by any aerosol device are trapped in the ventilator circuit and artificial airways. Moreover, the percentage of the emitted drug that is delivered past artificial airways as aerosol is lower with larger particle size. Therefore, aerosol devices producing particles of $<2 \mu \mathrm{m}$ are more efficient than those generating large particles during mechanical ventilation. ${ }^{33,43}$ Both pMDIs and nebulizers have equivalent aerosol delivery beyond the endotracheal tube (ETT) during mechanical ventilation. ${ }^{34}$ Although the size of aerosol particles with mesh nebulizers varies, ${ }^{44,45}$ a significant proportion are $<3.3 \mu \mathrm{m} .{ }^{45,46}$ The vapor pressure of the propellant mixture, ambient temperature, design of the valve stem and actuator orifice, and drug concentration affect aerosol particle size produced from the pMDI. ${ }^{47,48}$ For example, high vapor pressure of propellants generates finer aerosol particles, whereas a higher drug concentration increases the size of aerosol particles produced from the pMDI.

\section{Effect of Drug Formulation}

Inhaled $\beta$ agonists and anticholinergics are widely used in ICUs. However, there are other aerosolized medications that are used for the treatment of critically ill patients. Table 2 lists the classes of medications currently administered as aerosols in critical care. ${ }^{4,49}$ Previous research has shown that drug formulations influence the efficiency of aerosol devices. ${ }^{27,50-53}$ For example, Rau et al ${ }^{27}$ compared aerosol delivery via an albuterol and flunisolide CFC pMDIs using 5 different spacers and found that aerosol delivery with flunisolide was lower than with albuterol with all spacers tested (Table 3). Although newer drug solutions have been approved for specific nebulizers, clinicians may be confused about the best choice of aerosol device if the label does not specify which nebulizer to use for aerosol therapy or whether the same clinical outcome will occur if a nebulizer other than those used in clinical trials is used. Moreover, mixing drug formulations in the same nebulizer cup can be an issue if the combined formulations are not compatible. ${ }^{54-57}$

\section{Factors Affecting the Performance of Aerosol Devices}

\section{Nebulizer-Related Factors}

Nebulizer Type. Previous studies reported that both nebulizer type and different batches of the same brand of 
Table 2. Class of Medications Administered as Aerosol to Intubated Patients

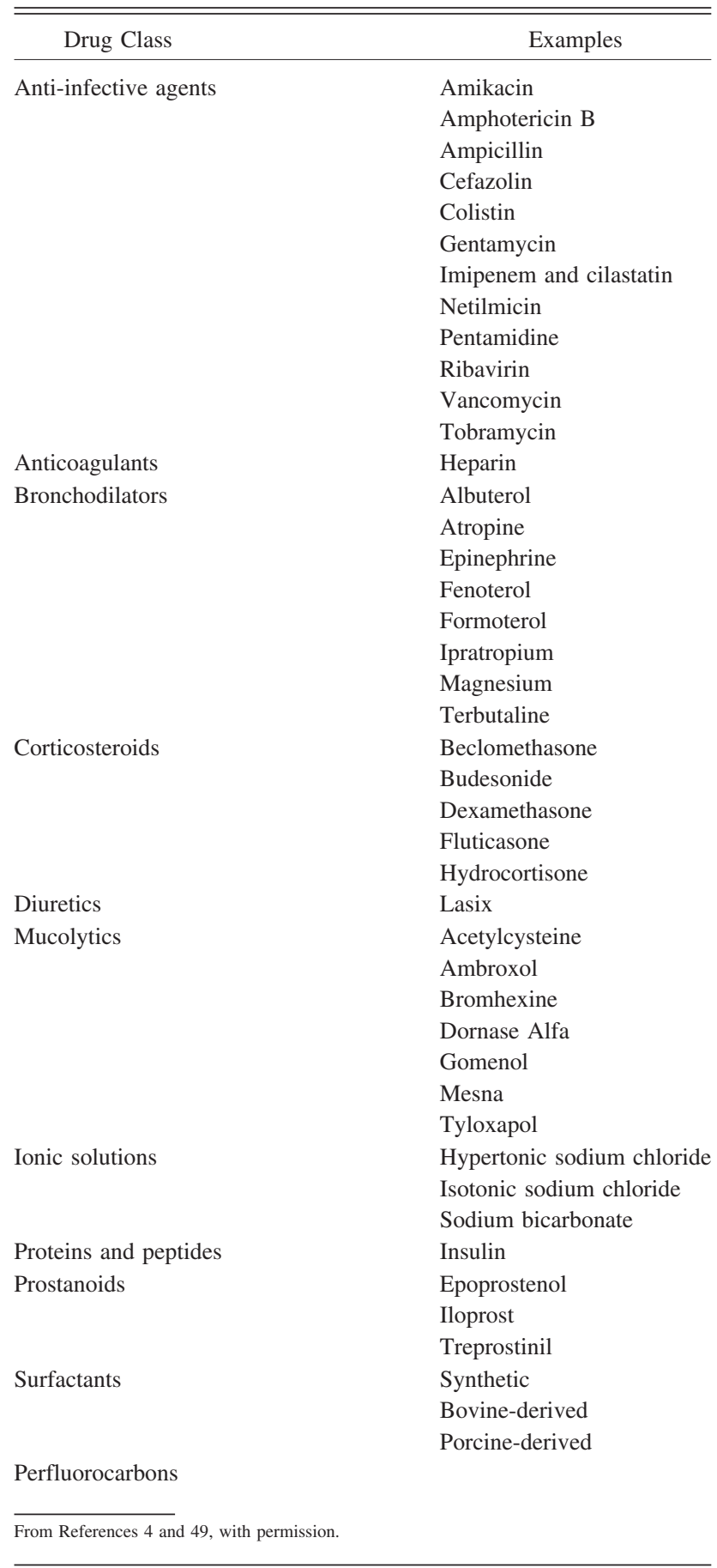

nebulizer caused variability in aerosol drug delivery to ventilator-dependent subjects. ${ }^{41,58-61}$ Output characteristics of jet nebulizers such as nebulization time and percent output in a respirable range vary greatly, affecting the delivery efficiency of the device during mechanical ventilation. ${ }^{58,59}$ It is well known that jet nebulizers are less efficient than mesh and ultrasonic nebulizers. Although
Table 3. Effect of the Type of pMDI and Spacer on Drug Delivery Efficiency

\begin{tabular}{lccccc}
\hline \hline \multicolumn{1}{c}{ Drug } & Hudson RCI & MiniSpacer & AeroVent & ACE & MediSpacer \\
\hline Albuterol & 12.0 & 17.2 & 17.7 & 30.0 & 31.8 \\
Flunisolide & 5.0 & 11.4 & 12.4 & 13.1 & 21.0 \\
& & & \\
Values are expressed as the percent nominal dose. From Reference 27. \\
pMDI = pressurized metered-dose inhaler \\
\hline
\end{tabular}

mesh and ultrasonic nebulizers are more expensive than jet nebulizers, they provide higher rates of nebulization in a shorter period of time. ${ }^{9,16,17}$ There are other disadvantages of using jet nebulizers in ventilator-dependent patients. For example, jet nebulizers may cause circuit contamination, ${ }^{62}$ reduce patient ability to trigger the ventilator, ${ }^{63}$ and change ventilator parameters such as tidal volume $\left(\mathrm{V}_{\mathrm{T}}\right)$ and airway pressure if they are not powered by the ventilator. Jet nebulizers are cheap, mass-produced, and for single-patient use, but they vary in performance, which is an important issue for the delivery of inhaled medications to critically ill patients.

Residual Volume. Residual volume, also known as dead volume, refers to the amount of drug that remains in the nebulizer at the end of aerosol therapy. Residual volume ranges from 0.5 to $2.5 \mathrm{~mL}$ depending on the type of nebulizer used. As residual volume increases, aerosol delivery to patients receiving mechanical ventilation decreases. The residual volumes of jet nebulizers are greater than those of ultrasonic and mesh nebulizers. ${ }^{14,44,64-67}$ This is a major factor associated with the lower aerosol delivery efficiency of jet nebulizers.

Fill Volume. Previous studies have reported that fill volume impacts aerosol delivery. ${ }^{41,68}$ Fill volume and aerosol output from jet nebulizers are directly related. Because nebulizers have a fixed residual volume, increasing the fill volume reduces the proportion of residual volume within the nebulizer cup and improves aerosol delivery. However, treatment time increases with a greater fill volume. Jet nebulizers do not function well with fill volumes of $<2 \mathrm{~mL}$ unless they are specifically designed for smaller fill volumes; therefore, a fill volume of $4-5 \mathrm{~mL}$ is recommended to increase output from jet nebulizers. ${ }^{41}$

Intermittent or Continuous Nebulization. Although jet nebulizers are usually operated continuously using pressurized gas from a 50-psi wall outlet or gas cylinder, it is also possible to operate them intermittently by driving pressure and gas flow from the ventilator. Intermittent nebulization generates aerosols only in inspiration and eliminates changes in ventilator parameters during aerosol therapy. However, it is important to note that the delivery 
efficiency of nebulizers may be affected by the lower driving pressure provided by the ventilator and the time gap between the powering of the nebulizer and aerosol generation. ${ }^{69}$

Previous research has produced some conflicting results on the effects of intermittent and continuous nebulization in aerosol delivery during mechanical ventilation. For example, both Miller et al ${ }^{70}$ and Hughes and $\mathrm{Saez}^{71}$ found that intermittent nebulization during mechanical ventilation provided as much as 4-fold greater inhaled dose compared with continuous nebulization in simulated adult lung models of mechanical ventilation. However, Sidler-Moix et $\mathrm{al}^{72}$ reported that in a pediatric ventilator circuit, continuous nebulization was greater than intermittent nebulization during inspiration, but less than intermittent expiratory nebulization. Wan et al ${ }^{73}$ compared 3 nebulization modes (inspiratory intermittent, continuous, and expiratory intermittent) on aerosol delivery using adult and pediatric in vitro lung models with a jet nebulizer placed proximal to the ventilator. They found no significant differences in aerosol deposition among the 3 modes in either lung model. Due to conflicting results in previous research, there is a significant need for more clinical research on this subject.

Nebulizer Placement in the Ventilator Circuit. Previous in vitro studies in adult and pediatric models found that jet nebulizer placement in the inspiratory limb farther away from the subject improved aerosol delivery during mechanical ventilation due to the reservoir effect of ventilator tubing, which accumulates aerosol between breaths. ${ }^{19,40,71,74}$ Moraine et $\mathrm{al}^{75}$ showed that the placement of a mesh nebulizer near the ventilator before the humidifier did not affect the urinary excretion of ipratropium bromide compared with its attachment to the Yadapter in the inspiratory circuit. However, both Berlinski and Willis ${ }^{74}$ and Ari et al ${ }^{18,19}$ showed that in the presence of bias flow, placement of a vibrating mesh nebulizer at the ventilator improved delivery efficiency in adults and children. This may not be the case with infant ventilator circuits.

Gas Flow and Density. Each model of jet nebulizer has different specifications for the flow that needs to be used for the operation during aerosol therapy. It ranges from 2 to $10 \mathrm{~L} / \mathrm{min}$ and is stated on the device label. Increasing gas flow to power the jet nebulizer improves aerosol output and decreases particle size, whereas a lower gas flow decreases nebulizer performance during therapy while increasing treatment time. When additional gas flow is used to operate the jet nebulizer during mechanical ventilation, the ventilator settings and alarms should be adjusted for patient safety. This is more of a factor in infants and pediatric circuits. Unlike jet nebulizers, mesh and ul- trasonic nebulizers are powered by electricity and are not affected by gas flow.

A gas that has a lower density than air or oxygen will decrease turbulent or transitional flow, which will lead to an increase in aerosol deposition in ventilator-dependent patients. According to Fink et al, ${ }^{31}$ the use of heliox (80:20 helium-oxygen mixture) in a dry ventilator circuit increases aerosol delivery by $50 \%$ compared with $100 \%$ oxygen.

\section{Pressurized Metered-Dose Inhaler-Related Factors}

Priming and Shaking pMDIs. Although there have been improvements in the valve design of pMDIs, all manufacturers still suggest priming pMDIs before first use and after specified periods of time between uses. ${ }^{76}$ Therefore, priming the pMDI before first treatment and every time when it has not been used for $>24 \mathrm{~h}$ is suggested. ${ }^{5}$ Shaking pMDIs before actuation is also important for efficient treatment. Even with HFA propellants, some pharmaceutical companies manufacturing pMDIs still suggest shaking the pMDI before aerosol therapy. According to Everard et $\mathrm{al}, 77$ total and respirable doses with pMDIs are reduced by $26 \%$ and $36 \%$, respectively, if the pMDI is not shaken before use. When a pMDI stands overnight, the medications in the pMDI formulation separate from their propellants, leading to a decrease in emitted and respirable doses. Also, storing pMDIs stem-down decreases the dose given with the first actuation by $25 \%$, despite shaking the pMDI before use. When the pMDI canister is kept in the inverted position, with the valve below the container, the force of gravity helps refill the metering valve before next actuation. Thus, clinicians should shake a pMDI before the first actuation, and then they can continue to use the same pMDI for up to 8 actuations because sequential use of the pMDI over a short time period does not cause a reduction in emitted dose. ${ }^{31}$

Timing of pMDI Actuation. Delay between a pMDI actuation and inspiration decreases aerosol deposition due to sedimentation and electrostatic charge. ${ }^{78-80}$ Therefore, pMDI actuation must be synchronized with the onset of inspiration for successful aerosol drug delivery to critically ill patients. The timing of pMDI actuation is very important for the dose of aerosolized drugs delivered. Failure to synchronize pMDI actuation with inspiration decreases aerosol delivery by $35 \% .{ }^{34}$ Although pharmaceutical companies usually recommend a 1 -min wait period between pMDI actuations, it has been reported that actuation of pMDIs at 15 -s intervals results in emitted doses similar to those at 1-min interval. ${ }^{31}$ However, 2 or more rapid actuations of a pMDI may lead to a decrease in drug delivery due to turbulence and coalescence of particles. ${ }^{77}$ 
Spacer. Several spacers with different designs and sizes are used for aerosol drug delivery to ventilator-dependent patients (see Fig. 1). Previous research has shown that differences in spacer designs and sizes impact aerosol deposition during mechanical ventilation. ${ }^{27,35,81,82}$ Aerosolized medications can build up on the walls of plastic spacers due to inertial impaction, gravitational sedimentation, and electrostatic charge. Large-volume spacers retain more of the aerosols delivered by pMDIs compared with small-volume spacers, decreasing the amount of aerosol available from the pMDI. ${ }^{83}$ If a spacer is manufactured from a non-electrostatic material, aerosols remain suspended for longer periods within the spacer. Thus, there is no substantial loss of drug to the walls of metal or nonelectrostatic spacers even when inhalation is delayed by $2-5 \mathrm{~s}$.

Rau et $\mathrm{al}^{35}$ compared the efficiency of 3 different spacer setups: (1) an elbow adapter attached to an ETT, (2) an in-line spacer between an ETT and a Y-adapter, and (3) a chamber spacer (AeroVent, Monaghan Medical, Plattsburgh, New York) connected to a Y-adapter in the inspiratory limb. Aerosol depositions obtained with these settings were $7.3 \%, 29 \%$, and $32.1 \%$, respectively. According to other studies in the literature, chamber-shaped in-line spacers increased aerosol drug delivery by up to 6-fold compared with either an elbow adapter or a unidirectional spacer. ${ }^{35,81,84}$ Aerosol delivery with a bidirectional spacer is greater than with a unidirectional spacer during mechanical ventilation. ${ }^{27}$ Also, it is important to match the size of the pMDI canister stem with the spacer required to connect to the ventilator circuits because the size of the canister stem differs for each pMDI, and the efficiency of aerosol delivery is influenced by its placement in the spacer.

Placement of pMDI in the Ventilator Circuit. Aerosol device position in the ventilator circuit impacts the efficiency of the device during mechanical ventilation. Ari et al ${ }^{19}$ compared 3 pMDI positions in a heated/humidified ventilator circuit in a simulated adult lung model: (1) between the ETT and Y-adapter, (2) $15 \mathrm{~cm}$ from the Yadapter, and (3) before the humidifier. Deposition efficiencies obtained with the pMDI in these positions were $7.6 \%$, $17 \%$, and $2.5 \%$, respectively. Therefore, placement of the pMDI spacer 6 inches from the ETT was suggested because delivering aerosolized medications with the pMDI at this position not only increased aerosol delivery to ventilator-dependent subjects but also produced improved clinical responses. ${ }^{19,30,35,85,86} \mathrm{~A}$ chamber spacer placed 6 inches from the ETT provided efficient drug delivery in ventilator-dependent subjects and led to a significant response to bronchodilator administration via a pMDI. ${ }^{85}$ Although the best location for aerosol devices should be confirmed by well-designed clinical studies, the available in vitro studies have found that inhaled dose was greater with the placement of a jet nebulizer before the humidifier, whereas a spacer with a pMDI can be placed 6 inches from the Yadapter in the inspiratory limb during mechanical ventilation. Also, placing the pMDI spacer 6 inches from the artificial airway increased aerosol delivery, ${ }^{18,86}$ which may lead to good clinical response in ventilator-dependent patients.

\section{Factors Affecting Aerosol Drug Delivery to Ventilator-Dependent Patients}

Although aerosol therapy is commonly employed for critically ill patients, many factors influence aerosol drug delivery to ventilator-dependent patients, and it is important to understand the effect of these factors on aerosol drug delivery in critical care. Previous studies showed that the ventilation mode, breathing parameters, heat and humidity, gas density, and artificial airways influenced aerosol delivery to critically ill subjects. ${ }^{18,19,31,87-89}$ The following section describes contributing factors that affect aerosol drug delivery during mechanical ventilation: ventilation mode, ventilator parameters, heat and humidity, gas density, artificial airways, and right-angle elbow adapters.

Ventilation Mode. Previous research has shown that ventilator parameters impact aerosol drug delivery during mechanical ventilation..$^{31,89,90}$ Fink et al ${ }^{31}$ compared the effects of different ventilation modes, including controlled mechanical ventilation, continuous mandatory ventilation, pressure support, and CPAP, on aerosol drug delivery using a pMDI with a chamber in an in vitro lung model. They found more aerosol deposition within the lower respiratory tract with CPAP than with controlled mechanical ventilation. According to Andersen and Klausen, ${ }^{90}$ the use of PEEP during aerosol therapy improved lung function in spontaneously breathing adults more than administering therapy without PEEP. Hess et al ${ }^{89}$ compared pressure control and volume control ventilation in albuterol delivery using an in vitro adult lung model. They found that aerosol delivery via a nebulizer in the mode of continuous aerosol generation was influenced by inspiratory time and inspiratory flow pattern, whereas aerosol deposition obtained from a pMDI synchronized with onset of inspiration was not influenced by these parameters.

Ventilator Parameters. $\quad V_{T}$ is not directly proportional to aerosol drug delivery during mechanical ventilation as long as the $\mathrm{V}_{\mathrm{T}}$ is greater than the internal volume of the ventilator tubing and artificial airways. ${ }^{6,31}$ Moreover, it is essential to note that a $\mathrm{V}_{\mathrm{T}}$ of $>8-10 \mathrm{~mL} / \mathrm{kg}$ can result in volutrauma and should not be used to improve the delivery 
efficiency of aerosol devices during mechanical ventilation. ${ }^{88}$

Inspiratory time is directly related to aerosol deposition in ventilator-dependent patients. ${ }^{31,87,91}$ Increasing inspiratory time leads to increases in aerosol delivery. However, the impact of inspiratory time is more apparent with the use of nebulizers that continuously generate aerosols than with pMDIs, which generate aerosol over a very short period of time. Also, increasing the duty cycle during mechanical ventilation improves aerosol deposition in ventilator-dependent patients. ${ }^{31,92}$ Although the use of a duty cycle $\geq 0.3$ is suggested for aerosol therapy during mechanical ventilation, it is important to monitor the degree of intrinsic PEEP and exercise caution with this practice because it may worsen dynamic hyperinflation in patients with air-flow limitation. 6,88

According to Fink et al, ${ }^{31}$ decreasing inspiratory flow from 80 to $40 \mathrm{~L} / \mathrm{min}$ improved aerosol deposition by $>2$ fold in subjects receiving ventilatory support. Using high inspiratory flow during mechanical ventilation creates transitional and turbulent flows in the airways that make aerosols deposit in the ventilator circuit and in the artificial airway. Because lower inspiratory flows increase aerosol delivery to ventilator-dependent patients, peak inspiratory flows should be decreased as much as possible if this is tolerated by the patient. Although improving aerosol delivery to ventilator-dependent patients is possible with an inspiratory flow of $40-50 \mathrm{~L} / \mathrm{min}$, it is also essential to minimize the intrinsic PEEP that may result from using lower inspiratory flows. 6,88

Inspiratory waveform also affects aerosol drug delivery to patients receiving mechanical ventilation. For example, when the same peak flow is used, a sinusoidal or descending waveform delivers more aerosols than a square waveform as a result of the sudden onset and duration of peak flow associated with turbulence.

Bias flow is the breath-triggering mechanism used during mechanical ventilation to decrease the patient work of breathing. An in vitro study conducted by Ari et al ${ }^{19}$ showed that increasing bias flow from 2 to $5 \mathrm{~L} / \mathrm{min}$ decreased albuterol delivery with jet and mesh nebulizers in an adult mechanical ventilation model. Using a bias flow of $2 \mathrm{~L} / \mathrm{min}$ or less is recommended during continuous nebulization of ventilator-dependent patients because bias flow dilutes the aerosol in the ventilator circuit and increases washout of the aerosol during expiration. In contrast to nebulizers, aerosol delivery with a pMDI is not impacted by bias flow when pMDI actuation is synchronized with the beginning of inspiration. ${ }^{31}$

Heat and Humidity. It is well known that heat and humidity impact aerosol drug delivery during mechanical ventilation. In vitro studies have reported up to $40 \%$ less aerosol deposition with heated and humidified gas com- pared with unheated and non-humidified ventilator circuits. ${ }^{19,31,32,87,91,93}$ However, although using an unheated and non-humidified ventilator circuit leads to a significant improvement in aerosol deposition in the lung, ventilatordependent patients need heated and humidified gas to avoid drying airway mucosa and to promote mucus clearance during mechanical ventilation. ${ }^{94,95}$

The decrease in aerosol deposition with a heated and humidified ventilator circuit is due to changes in aerosol particle size during mechanical ventilation. For example, Miller et al ${ }^{70}$ found that providing humidity during aerosol therapy in ventilator-dependent subjects increased particle size from $1.5 \pm 0.1$ to $2.3 \pm 0.2 \mu \mathrm{m}$. However, Lange and Finlay ${ }^{96}$ reported that the reduction in aerosol deposition was directly related to the mole fraction of water vapor in the inspired air instead of the heat and humidity of the inhaled gas. According to their hypothesis, the main reason for excessive drug loss during mechanical ventilation is not hygroscopic growth but an interaction between the water molecules in the air and the surfactant (pMDI) present in the propellant/drug suspension.

Lin et al ${ }^{97}$ studied aerosol delivery via a pMDI with a spacer during mechanical ventilation using a heated-wire circuit attached to a heated humidifier. They operated the humidifier for $3 \mathrm{~h}$ during mechanical ventilation and found that pMDI delivery efficiency did not decrease for $>1 \mathrm{~h}$ after turning on the humidifier. They also found that turning off the humidifier for $10 \mathrm{~min}$ before aerosol therapy did not improve aerosol delivery via a pMDI attached to a spacer. According to their findings, there was a reduction in aerosol delivery when substantial condensation formed in the ventilator tubing and the pMDI spacer.

Although humidity has been associated with reduced aerosol delivery to ventilator-dependent patients, neither removing the heated humidifier from the circuit nor turning off the humidifier before aerosol therapy is recommended. ${ }^{4-7,97}$ Delivery efficiency can be increased by achieving optimum technique during aerosol therapy and increasing the dose when a heated humidifier is used. Although using a dry circuit may be cost-effective with expensive drugs such as antibiotics, it is important to complete aerosol therapy in $<10 \mathrm{~min}$ to minimize the effect of dry gas on the airway mucosa. ${ }^{65}$ Therefore, clinicians should consider increasing the dose instead of turning off the heated humidifier when they use inexpensive drugs such as bronchodilators for aerosol therapy during mechanical ventilation.

Heat-and-moisture exchangers (HMEs) are also used to provide heat and humidity to mechanically ventilated patients. Because the filter in the HME acts as a barrier to drug delivery, HMEs should not be placed between the artificial airway of the patient and the aerosol device. Disconnection of the ventilator circuit to remove the HME 


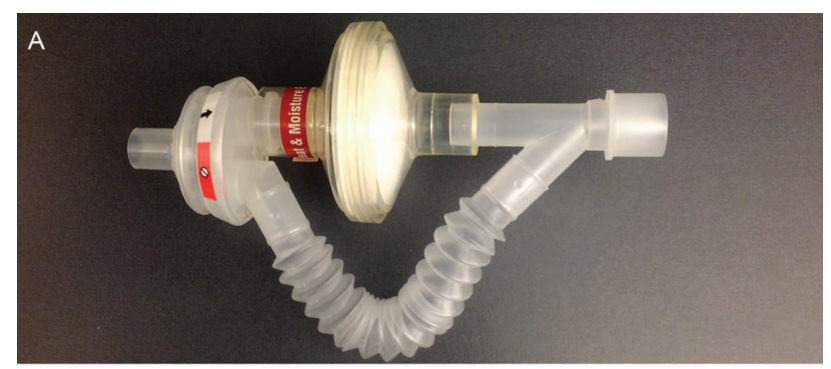

B
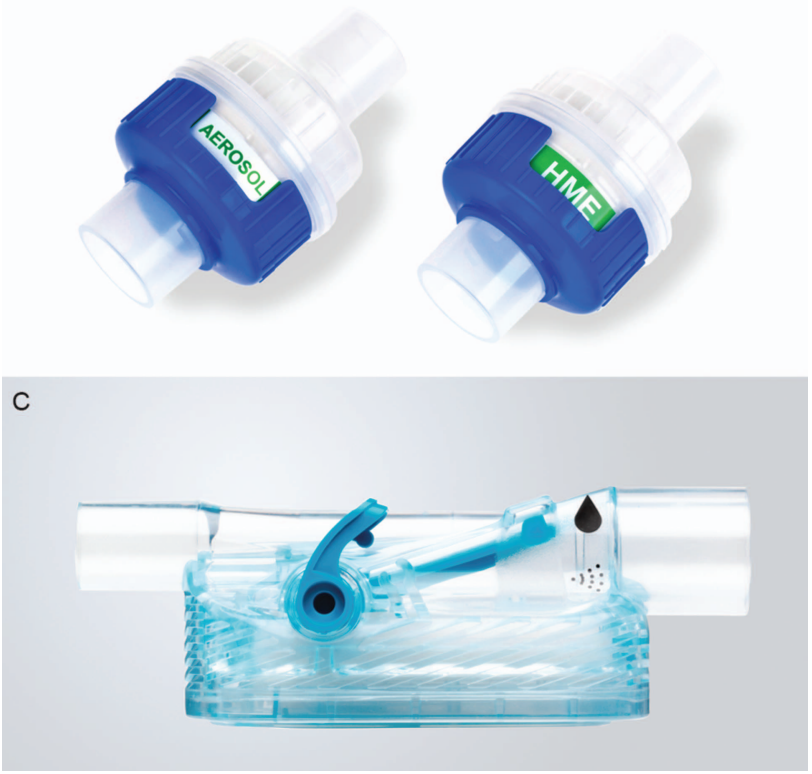

Fig. 2. Heat-and-moisture exchangers (HMEs) designed for aerosol delivery during mechanical ventilation. A: CircuVent HME/hygroscopic condenser humidifier bypass with an HME, courtesy Hudson RCI. B: Humid-Flo HME, courtesy Hudson RCI. C: AirLife bypass HME, courtesy CareFusion.

from the circuit before aerosol therapy interrupts the ventilation of critically ill patients and may cause derecruitment of the lungs, which might take considerable time to re-establish. To overcome issues with the use of standard HMEs during inhalation therapy, new HMEs have been designed for aerosol delivery (HME-AD) to ventilatordependent patients. Figure 2 shows the different types of HME-ADs available on the market. Although HMEADs differ in design, they all have 2 configurations: (1) HME configuration and (2) aerosol configuration. The HME configuration functions like a standard HME, whereas the aerosol configuration bypasses the HME configuration to deliver aerosolized medications during mechanical ventilation. However, an in vitro study showed some variation in drug delivery depending on the design and composition of HME-ADs. ${ }^{98}$ Further research is thus needed to determine the delivery efficiency of HME-ADs with different aerosol delivery devices during mechanical ventilation.
Gas Density. Previous studies have reported that heliox improves aerosol deposition by creating laminar flows in the airways and decreasing impaction losses caused by air-flow turbulence. ${ }^{37,98,100}$ According to Goode et al, ${ }^{37}$ 80:20 heliox improved aerosol delivery by $50 \%$ over oxygen alone. The delivery efficiency of aerosol devices during mechanical ventilation and the gas density in the ventilator circuit are inversely related. Although using a lower gas density increases aerosol delivery, it must be noted that this also impacts the performance of a jet nebulizer during inhalation therapy. Because heliox has lower density, it is not effective in generating aerosols with jet nebulizers. Therefore, heliox should not be used to power jet nebulizers. ${ }^{37,101}$ Tassaux et al ${ }^{102}$ reported that aerosol delivery to the lower airways increased by up to $50 \%$ with a jet nebulizer attached to a ventilator circuit containing heliox that was powered with oxygen at $6-8 \mathrm{~L} / \mathrm{min}$. It is also important to note that heliox may impact the function of the ventilator, and clinicians should test the ventilator with heliox to detect any malfunction before use to ensure patient safety during mechanical ventilation. ${ }^{37,101}$

Artificial Airways. Artificial airways affect aerosol drug delivery to ventilator-dependent patients. For example, aerosol deposition has been found to be significantly lower with smaller ETTs. ${ }^{92,103}$ Crogan and Bishop ${ }^{92}$ found that metaproterenol delivery through an ETT using a pMDI decreased with reduction of the inner diameter of the ETT. The percentage of aerosols exiting the ETT was 3\% for a 6.0-mm ETT compared with $6.5 \%$ for a 9.0-mm ETT. Because the inner diameter of an ETT is narrower than that of the oropharynx and trachea, aerosol drug deposition is decreased with reduction of the ETT inner diameter. This is especially significant in pediatric ETTs with inner diameters of 3-6 mm. ${ }^{82,104}$ The delivery efficiency of a jet nebulizer with a 7-mm inner diameter ETT was similar compared with a 9-mm inner diameter ETT in ventilatordependent subjects. ${ }^{105}$

The majority of studies evaluating the impact of artificial airways on aerosol delivery have been on ETTs; aerosol deposition via tracheostomy tubes has not been studied as much. However, O'Riordan et al ${ }^{87}$ examined aerosol delivery to mechanically ventilated subjects with a tracheostomy using a radiolabeled aerosol in vivo. They reported that the tracheostomy tube was not a barrier to lung deposition because $<3 \%$ of aerosols deposited on the tracheostomy tube.

Right-Angle Elbow Adapter. Many ventilator circuits include a right-angle adapter that is positioned between the artificial airway and the Y-adapter of the circuit. Research has shown that removing the right-angle adapter from the circuit improves aerosol delivery during mechanical ventilation. ${ }^{33}$ However, the efficiency gained by this practice 
might be lost farther down the airway of ventilator-dependent patients.

\section{Factors Affecting Aerosol Delivery in Spontaneously Breathing Patients With Artificial Airways}

Although artificial airways are used for drug delivery either by administration of aerosolized drugs or by instillation of liquid medications, aerosol drug delivery to spontaneously breathing patients with artificial airways is not well understood. Only a few in vitro studies have been done on aerosol delivery through a tracheostomy tube, ${ }^{106-109}$ along with a few case reports on methods used to adapt pMDIs to patients with tracheostomies. ${ }^{110-112}$ Previous studies found that a measurable amount of aerosol was delivered through the tracheostomy tube regardless of the type of aerosol device used, and aerosol delivery through the tracheostomy tube ranged from 1 to $45 \%$ depending on a variety of measurement conditions. ${ }^{106-109}$

Factors affecting pulmonary deposition of aerosols in patients receiving mechanical ventilation are different from those in spontaneously breathing patients. Previous studies have reported that albuterol delivery through artificial airways is influenced by the type and material of artificial airways, electrostatic charge, inner cannula of the tracheostomy tube, type of aerosol device, type of patient interface, and use of bias flow in spontaneously breathing subjects with artificial airways. ${ }^{106-109,113-115}$

Type of Artificial Airway. Two types of artificial airway are commonly used for long-term airway management of critically ill patients. Although ETTs are used for initial airway management in patients receiving mechanical ventilation, tracheostomy tubes are used in patients requiring long-term mechanical ventilation and in special conditions that preclude the use of an ETT. Ari et $\mathrm{al}^{107}$ compared the delivery of albuterol through an ETT and a tracheostomy tube in simulated spontaneously breathing adults. Their study showed that aerosol delivery through a tracheostomy tube was greater than that through an ETT due to the shorter length of the tracheostomy tube.

Material of Artificial Airways. Artificial airways are made of different materials. For example, tracheostomy tubes are made of polyvinyl chloride, silicone, or silver, whereas ETTs are usually made of polyvinyl chloride and, less frequently, silicone. Because artificial airways made of polyvinyl chloride have the ability to attract aerosol particles to the inner walls of the tubes, electrostatic charge may be an issue. Although it is assumed that the material used to manufacture artificial airways affects aerosol deposition in critically ill patients, no research has been reported on the impact of the tube material and electrostatic charge on aerosol drug delivery with artificial airways.

Inner Cannula of the Tracheostomy Tube. Tracheostomy tubes with an inner cannula are commonly used in critically ill patients. Pitance et al ${ }^{115}$ studied the effect of inner cannulas on aerosol delivery in an adult lung tracheostomy model using cannulas with inner diameters of 6.5 , $8,8.5$, and $10 \mathrm{~mm}$. They found a negative correlation between the cannula inner diameter and aerosol lost in the cannula. Because removing the inner tracheostomy cannula improved aerosol delivery by up to $31 \%$, they recommended removing the tracheostomy cannula before aerosol therapy in patients with tracheostomy.

Type of Aerosol Device. Piccuito and Hess ${ }^{106}$ compared in vitro aerosol delivery via a jet nebulizer and pMDI using different interfaces in an adult lung tracheostomy model. In their study, the delivery efficiency of a pMDI with a valved holding chamber was greater than with a jet nebulizer. However, they also reported that the absolute dose obtained with the jet nebulizer was more than with the pMDI because of the greater nominal dose placed in the nebulizer cup. If a large dose is needed, the jet nebulizer might be a better option than a pMDI. Alternatively, clinicians can increase the number of actuations given by a pMDI.

Pitance et al ${ }^{115}$ examined the delivery efficiency of 3 jet nebulizer configurations: vented, unvented alone, and unvented with corrugated tubing attached to the expiratory limb of the T-piece. They found that an unvented jet nebulizer with corrugated tubing was the best configuration among those tested. They recommended using corrugated tubing attached to the T-piece with the jet nebulizer to increase aerosol delivery through a tracheostomy tube.

Type of Patient Interface. There are different types of patient interfaces used for patients with artificial airways. Although a jet nebulizer can be used with a tracheostomy tube, T-piece, and manual resuscitation bag, a pMDI with a valved holding chamber can be combined with a T-piece and manual resuscitation bag. Piccuito and Hess ${ }^{106}$ tested a jet nebulizer with a T-piece and tracheostomy tube and found that the most efficient aerosol interface was the T-piece in a spontaneously breathing adult lung tracheostomy model. Likewise, Ari et al ${ }^{107}$ reported greater aerosol delivery with a jet nebulizer attached to a T-piece compared with a tracheostomy mask. When higher levels of drug delivery are needed, as in patients with severe bronchoconstriction, clinicians may consider capping one end of the T-piece and using a manual resuscitation bag attached to the other end for spontaneously breathing patients with tracheostomy. Ari et al ${ }^{107}$ also found that this method of aerosol delivery was associated with 
a 3-fold increase in drug delivery with a manual resuscitation bag, regardless of the type of artificial airway tested.

Comparing 3 different setups used for pMDIs (in-line spacer, valved T-piece with valve distal to spacer, and valved T-piece with valve proximal to spacer), Piccuito and Hess ${ }^{106}$ found that the pMDI was most efficient when used with a valved T-piece with the valve proximal to the spacer. Moving the valve from the distal to proximal position increased aerosol delivery by 2 -fold.

Use of Bias Flow. Patients with a tracheostomy routinely use a high-flow oxygen delivery device. Piccuito and Hess ${ }^{106}$ found that the amount of aerosol deposition was significantly reduced when the jet nebulizer was connected in-line with a high-flow oxygen delivery device due to aerosol waste to the ambient air. Turning off the high-flow oxygen device before aerosol therapy resulted in an increase in drug delivery of up to 3-fold. Therefore, they suggested using a jet nebulizer without additional gas flow given by the oxygen system for spontaneously breathing patients with a tracheostomy.

\section{Effect of Disease State and Severity}

Critical care departments provide intensive treatment and monitoring for patients in critically ill or unstable conditions. The efficiency of aerosol devices used in pulmonary critical care is influenced by a number of factors that are explained above. Previous in vitro studies have had significant impact on the knowledge of clinicians by exploring the effects of these factors on aerosol drug delivery to critically ill patients. However, although current inhaler devices are designed to generate aerosol particles in the respirable range and consistent amounts of drug can be delivered to a test lung or lung model in bench studies, clinicians may still fail to deliver aerosolized medications to the lungs of critically ill patients because of disease state and severity. Thus, patients may receive little or no benefit from the device. Clinical research is needed to understand the effects of disease state and severity on aerosol drug delivery in critical care, but unfortunately, there has been little such research.

\section{Device Selection}

Previous studies have reported that nebulizers and pMDIs have equal therapeutic effects in subjects when the drug is available in both formats and administered properly. ${ }^{116,117}$ However, it is important to note that such studies are largely based on bronchodilators, and the delivery efficiency of all devices and interfaces is not the same under all conditions. Therefore, clinicians should consider a series of factors that are explained below when

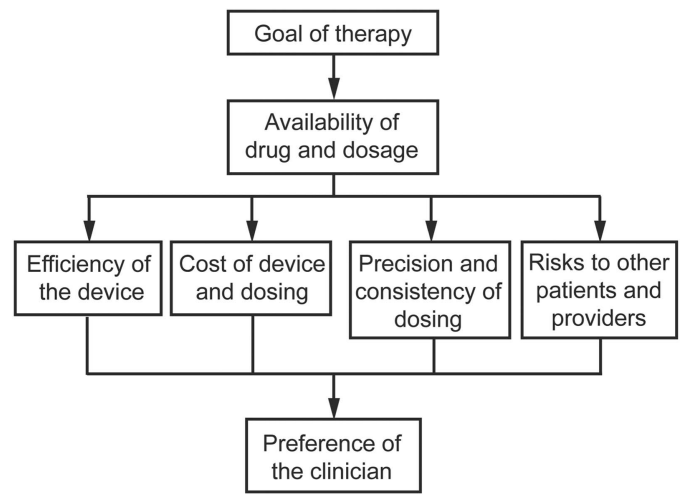

Fig. 3. Flow diagram showing steps for the selection of an aerosol device in critical care.

selecting the best aerosol device for their ventilatordependent patients (Fig. 3).

\section{Goal of Therapy}

The indications for aerosol therapy in pulmonary critical care have rapidly expanded over the years. Aerosol therapy has several advantages, including direct delivery of drug to the site of action, rapid onset of action, lower dose required than with systemic administration to produce desired clinical outcomes, and minimum systemic adverse effects. The selection of an aerosol device depends upon the needs of the patient and the intent of the clinician. Once clinicians are clear about the goal of aerosol therapy in critically ill patients, they can determine the desired therapeutic outcomes that are patient-specific.

\section{Availability of Drug and Dosage}

A variety of drugs are available for the treatment of critically ill patients. Although pMDIs are largely limited to bronchodilators and corticosteroids, nebulizers are used to deliver, in addition, antibiotics, surfactant, mucolytics, and prostaglandins. If a drug formulation is available only with one type of aerosol device, aerosol device selection is simple because there is no other choice. When drugs such as bronchodilators and corticosteroids can be administered with both nebulizers and pMDIs, selection of the device should be made based on the precision and consistency of dosing as well as the efficiency of the device. Also, if a patient needs higher doses, clinicians have 2 choices: they can use a nebulizer, or they can deliver multiple doses with a pMDI attached to a spacer. ${ }^{118}$

\section{Cost of Device and Dosing}

Cost of dosing is an important factor in device selection. In the current climate of cost containment, a device that is 
expensive is less likely to be used in critical care. Although previous studies have found that bronchodilator administration is more cost-effective with pMDIs than with nebulizers, this may no longer hold true due to the transition from CFC pMDIs to HFA pMDIs. For example, 4 puffs of albuterol delivered from an HFA pMDI ( $\$ 140$ for 200 puffs) costs $\$ 2.80$, whereas a unit dose of albuterol given by a jet nebulizer costs less than $\$ 0.25$. It is also important to note that the time spent by respiratory therapists on aerosol therapy is a major consideration for cost analysis. ${ }^{119}$ Nevertheless, the drug options available with pMDIs are limited; pMDIs are a great option when the prescribed drug/dosage is available because they provide the desired clinical response.

\section{Precision and Consistency of Dosing}

Achieving a clinical response to an aerosolized medication depends on the amount of drug delivered to the lower airways, ${ }^{120,121}$ and this is affected by the precision and consistency of dosing. Although the total amount of drug delivered to the lungs with each device is important, the precision and consistency of dosing with an aerosol device need to be considered when selecting the best device and interface for critically ill patients. ${ }^{120}$ Loss of medications in the upper respiratory tract, ventilator circuit, and artificial airways can reduce the precision of dosing; therefore, it is important to reduce this drug loss while achieving targeted aerosol deposition in specific regions of the lung, such as peripheral airways and lung parenchyma. Consistency of dosing requires uniformity in the drug delivered with each aerosol device every time it is used with critically ill patients.

\section{Efficiency of the Device}

As mentioned previously, aerosol delivery devices are equally efficient if they are used correctly.,4,88,101,116,117,122 It is well known that the efficiency of an aerosol device depends on the size of drug particles generated. Both pMDIs and nebulizers generate aerosol particles in the range of 1-5 $\mu \mathrm{m}$. Although the aerosol delivered from the distal end of an ETT has a mass median aerodynamic diameter of $\sim 2 \mu \mathrm{m},{ }^{34}$ nebulizers that produce aerosols with a diameter of $<2 \mu \mathrm{m}$ are more efficient than nebulizers that generate larger particles. ${ }^{36,87,92}$ Also, $\sim 5 \%$ of aerosols produced by a $\mathrm{pMDI}^{33}$ are exhaled during mechanical ventilation compared with $7 \%$ of the nominal dose of aerosols generated by a nebulizer. ${ }^{87}$ It is important to note that an efficient device not only delivers a high proportion of the drug placed in the device to the lung of the patient but also minimizes waste of the expensive drugs used in critical care. ${ }^{16}$

\section{Risk to Patients and Providers}

Aerosol therapy with inhaled medications may create blockages in expiratory filters in ventilators and interfere with vital ventilator functions such as breath sensing. Moreover, aerosols given to ventilator-dependent patients may escape to the environment and create risks to health-care professionals, caregivers, and other patients. Aerosols generated by patients may also pose a greater risk of transmission of airborne diseases such as H1N1, severe acute respiratory syndrome, and tuberculosis. Therefore, it is important to use some form of high-efficiency particulate air filter in the expiratory limb of the ventilator circuit to reduce the escape of aerosols generated by the patient or an aerosol device. Also, the capability of a device to minimize the risk to patients and providers must be considered during the device selection process.

\section{Preference of Clinicians}

The time required for therapy, device cleaning, device portability, and ease of drug administration to critically ill patients determine the utilization of an aerosol device in critical care. Any aerosol device that is difficult to use or requires prolonged administration or frequent monitoring will not be preferred by clinicians. Despite the increasing use of pMDIs, nebulizers have been used in clinical settings for many years. Previous research has also shown that the majority of adult ICUs prefer pMDIs for the administration of bronchodilators in critically ill patients. ${ }^{49,123}$ According to a survey conducted in 70 countries, ${ }^{49} 43 \%$ of participants used nebulizers, whereas 55\% used pMDIs for aerosol drug delivery in ICUs. This may be because of their convenience, consistent dosing, and reduced chance of bacterial contamination. ${ }^{124-126}$ Reported uses of jet, ultrasonic, and mesh nebulizers were 55\%, 44\%, and $14 \%$, respectively. Although $87 \%$ of participants believed that ultrasonic nebulizers outperform jet nebulizers, $69 \%$ did not have any ideas about mesh nebulizers. ${ }^{49}$

\section{Optimum Technique}

Successful delivery of aerosolized medications to critically ill patients depends upon the type of aerosol device and the technique utilized during therapy. Therefore, physicians and health-care professionals working in pulmonary critical care must be adequately trained in the proper use of each aerosol device. Otherwise, patients will receive a suboptimal dose that will not be beneficial. Much has been published about aerosol delivery through ETTs in mechanically ventilated patients. Therefore, the optimum technique for aerosol therapy in ventilator-dependent patients is clear. A variety of methods are used to deliver aerosolized medications via a nebulizer or pMDI to spon- 
Table 4. Common Errors in Aerosol Device Use in the Treatment of Critically Ill Patients

\begin{tabular}{lll}
\hline \hline \multicolumn{1}{c}{ Nebulizers } & \multicolumn{1}{c}{ pMDIs } & \multicolumn{1}{c}{ Spacers } \\
\hline Failure to assemble device correctly & Failure to prime & Incorrect assembly of device \\
Incorrect flow & Failure to shake & Failure to remove electrostatic charge \\
Incorrect fill volume & Incorrect assembly of device & Delay between actuation and inspiration \\
Loss of dose during preparation & Multiple actuations during inhalation & Firing multiple doses into device
\end{tabular}

pMDIs $=$ pressurized metered-dose inhalers

Table 5. Problems, Causes, and Solutions During Aerosol Drug Delivery With Jet, Ultrasonic, and Mesh Nebulizers

\begin{tabular}{|c|c|c|}
\hline Problem & Causes & Solutions \\
\hline \multirow[t]{3}{*}{ Absent or low aerosol with jet nebulizers } & Loose or unattached connections & $\begin{array}{l}\text { Check the connections and make sure they are } \\
\text { properly attached }\end{array}$ \\
\hline & Inappropriate flow-meter setting & $\begin{array}{l}\text { Check the flow-meter setting and adjust the flow } \\
\text { accordingly }\end{array}$ \\
\hline & Obstruction in the orifice of the jet nebulizer & $\begin{array}{l}\text { Check the orifice of the jet nebulizer and clear } \\
\text { obstructions when needed }\end{array}$ \\
\hline \multirow[t]{4}{*}{ Mesh or ultrasonic nebulizer does not operate } & Incorrect battery installation & Check the battery installation and reinstall, if needed \\
\hline & Disconnection in external power source & $\begin{array}{l}\text { Check the connection with the AC adapter and } \\
\text { electrical output }\end{array}$ \\
\hline & Overheated unit & Turn off the unit, wait until it cools down, and restart \\
\hline & Malfunctioning electronics & Replace the unit \\
\hline \multicolumn{3}{|l|}{$\begin{array}{l}\text { From Reference } 15 \text {, with permission. } \\
\mathrm{AC}=\text { alternating current }\end{array}$} \\
\hline
\end{tabular}

taneously breathing patients with tracheostomy tubes. Unfortunately, there is no standard practice for delivering aerosols to this patient population. The optimum technique for administering aerosols in spontaneously breathing patients with artificial airways has not been well described. Table 4 lists common errors in aerosol device use in the treatment of critically ill patients, and Table 5 lists problems, causes, and solutions during aerosol drug delivery with nebulizers and pMDIs in critical care.

\section{Unmet Needs of Aerosol Medicine in Pulmonary Critical Care}

Although administration of aerosolized drugs in critical care has significantly improved over the years, unmet needs in this important treatment still exist. This can be divided into 3 categories: (1) drug development, (2) research on clinical outcomes, and (3) standards of practice.

\section{Drug Development}

Efficient delivery of aerosolized medications to critically ill patients has always been desirable. However, the aerosolized medications used in critical care are approved based on treatment of ambulatory patients. No medical aerosols have been approved specifically for administration to very sick patients who are ventilator-dependent and/or have artificial airways. Thus, there are opportunities for development of drugs to treat critically ill patients.

\section{Research on Clinical Outcomes}

Previous research has focused on understanding factors that affect aerosol delivery and techniques of mitigating their negative effects during aerosol therapy in critically ill patients. Clinical studies in support of previous in vitro research are limited. Therefore, it is important to conduct clinical research to confirm the benefits of aerosolized medications in both ventilator-dependent patients and spontaneously breathing patients with artificial airways. In addition, we need more information on the effect of inhaled drugs on physiologic variables, cardiovascular and metabolic effects, and clinical outcomes such as duration of mechanical ventilation and stay in ICUs. A cost-benefit analysis should be done for each inhaled drug and aerosol technologies if patient outcomes show improvement after aerosol therapy. 


\section{Aerosol Therapy in Pulmonary Critical Care}

\section{Standards of Practice}

Research to determine the effectiveness of aerosolized medications and the best dosing schedule is needed to establish standards of practice for aerosol therapy in not only ventilator-dependent patients but also spontaneously breathing patients with artificial airways. Although there are some studies on bronchodilators, the effectiveness of other aerosolized medications, such as surfactants, antibiotics, and mucolytics, needs to be established through randomized controlled trials in critically ill patients. Effective aerosol therapy in critical care may require modifications in the configuration of device, dose, and frequency of aerosolized medications prescribed, but there is currently little guidance or information on standards of practice in aerosol therapy. With insufficient information on indication, dose, frequency, and optimum method of administration of different inhaled medications, there is a need for the development of standards of practice in pulmonary critical care.

\section{Summary}

Aerosol therapy is commonly used in pulmonary critical care. Although inhaled $\beta$ agonists and anticholinergics are widely used in ICUs, other aerosolized medications are available for the treatment of critically ill patients. Previous studies have demonstrated that many factors influence aerosol deposition in the lower respiratory tract, and the effectiveness of aerosol therapy is technique-dependent. When clinicians understand the scientific basis of aerosol therapy and use a proper technique during the therapy, they can provide effective, consistent, and precise delivery of aerosolized medications. Future research should focus on drug/device development, clinical data on patient outcomes, and standards of practice in critical care to provide adequate information on drug and dosing regimens for critically ill patients, which will help clinicians achieve effective and safe delivery of aerosolized medications in critical care.

\section{REFERENCES}

1. Hess DR. Nebulizers: principles and performance. Respir Care 2000; 45(6):609-622.

2. Hess DR. Liquid nebulization: emerging technologies conference summary. Respir Care 2002;47(12):1471-1476.

3. Le Brun PP, de Boer AH, Heijerman HG, Frijlink HW. A review of the technical aspects of drug nebulization. Pharm World Sci 2000; 22(3):75-81

4. Fink J, Ari A. Aerosol therapy in intubated patients. Expert Opin Drug Deliv 2013;10(8):1077-1093.

5. Ari A, Fink JB, Dhand R. Inhalation therapy in patients receiving mechanical ventilation: an update. J Aerosol Med Pulm Drug Deliv 2012;25(6):319-332.
6. Ari A, Fink JB. Factors affecting bronchodilator delivery in mechanically ventilated adults. Nurs Crit Care 2010;15(4):192-203.

7. Ari A. Aerosol therapy for mechanically ventilated patients: devices, issues, selection \& technique. Clin Found 2012;14:1-12.

8. Phipps PR, Gonda I. Droplets produced by medical nebulizers. Some factors affecting their size and solute concentration. Chest 1990;97(6):1327-1332.

9. Dolovich MB, Dhand R. Aerosol drug delivery: developments in device design and clinical use. Lancet 2011;377(9770):1032-1045.

10. Rau JL. Design principles of liquid nebulization devices currently in use. Respir Care 2002;47(11):1257-1275; discussion 1275-1278.

11. Dhand R, Mercier E. Effective inhaled drug administration to mechanically ventilated patients. Expert Opin Drug Deliv 2007;4(1):47-61.

12. Nikander K, Turpeinen M, Wollmer P. The conventional ultrasonic nebulizer proved inefficient in nebulizing a suspension. J Aerosol Med 1999;12(2):47-53.

13. Steckel H, Eskandar F. Factors affecting aerosol performance during nebulization with jet and ultrasonic nebulizers. Eur J Pharm Sci 2003;19(5):443-455.

14. Harvey CJ, O’Doherty MJ, Page CJ, Thomas SH, Nunan TO, Treacher DF. Comparison of jet and ultrasonic nebulizer pulmonary aerosol deposition during mechanical ventilation. Eur Respir J 1997; 10(4):905-909.

15. Ari A. Nebulizers: an evaluation of nebulizers for better clinical practice. Eurasian J Pulmonol 2014;16:1-7.

16. Dhand R. New frontiers in aerosol delivery during mechanical ventilation. Respir Care 2004;49(6):666-677.

17. Dhand R. Nebulizers that use a vibrating mesh or plate with multiple apertures to generate aerosol. Respir Care 47(12):1406-1416, 2002; discussion 1416-1408.

18. Ari A, Atalay OT, Harwood R, Sheard MM, Aljamhan EA, Fink JB. Influence of nebulizer type, position, and bias flow on aerosol drug delivery in simulated pediatric and adult lung models during mechanical ventilation. Respir Care 2010;55(7):845-851.

19. Ari A, Areabi H, Fink JB. Evaluation of position of aerosol device in two different ventilator circuits during mechanical ventilation. Respir Care 2010;55(7):837-844.

20. Pitance L, Vecellio L, Leal T, Reychler G, Reychler H, Liistro G. Delivery efficacy of a vibrating mesh nebulizer and a jet nebulizer under different configurations. J Aerosol Med Pulm Drug Deliv 2010;23(6):389-396.

21. Rubin BK, Fink JB. Optimizing aerosol delivery by pressurized metered-dose inhalers. Respir Care 2005;50(9):1191-1200.

22. Labiris NR, Dolovich MB. Pulmonary drug delivery. Part II: the role of inhalant delivery devices and drug formulations in therapeutic effectiveness of aerosolized medications. Br J Clin Pharmacol 2003;56(6):600-612.

23. Newman SP. Principles of metered-dose inhaler design. Respir Care 2005;50(9):1177-1190.

24. Rau JL. The inhalation of drugs: advantages and problems. Respir Care 2005;50(3):367-382.

25. Rubin BK. Air and soul: the science and application of aerosol therapy. Respir Care 2010;55(7):911-921.

26. Hess DR. Aerosol delivery devices in the treatment of asthma. Respir Care 2008;53(6):699-723; discussion 723-725.

27. Rau JL, Dunlevy CL, Hill RL. A comparison of inline MDI actuators for delivery of a beta agonist and a corticosteroid with a mechanically-ventilated lung model. Respir Care 1998;43:705-712.

28. MacIntyre NR, Silver RM, Miller CW, Schuler F, Coleman RE. Aerosol delivery in intubated, mechanically ventilated patients. Crit Care Med 1985;13(2):81-84.

29. Fuller HD, Dolovich MB, Posmituck G, Pack WW, Newhouse MT. Pressurized aerosol versus jet aerosol delivery to mechanically ven- 


\section{Aerosol Therapy in Pulmonary Critical Care}

tilated patients. Comparison of dose to the lungs. Am Rev Respir Dis 1990;141(2):440-444.

30. Dhand R, Tobin MJ. Inhaled bronchodilator therapy in mechanically ventilated patients. Am J Respir Crit Care Med 1997;156(1):3-10.

31. Fink J, Dhand R, Duarte A, Jenne J, Tobin M. Aerosol delivery from a metered-dose inhaler during mechanical ventilation. An invitro model. Am J Respir Crit Care Med 1996;154(2):382-387.

32. Fuller HD, Dolovich MB, Chambers C, Newhouse MT. Aerosol delivery during mechanical ventilation: a predictive in-vitro lung model. J Aerosol Med 1992;5(4):251-259.

33. Fink JB, Dhand R, Grychowski J, Fahey PJ, Tobin MJ. Reconciling in vitro and in vivo measurements of aerosol delivery from a metered-dose inhaler during mechanical ventilation and defining efficiency-enhancing factors. Am J Respir Crit Care Med 1999;159(1): 63-68.

34. Diot P, Morra L, Smaldone GC. Albuterol delivery in a model of mechanical ventilation. Comparison of metered-dose inhaler and nebulizer efficiency. Am J Respir Crit Care Med 1995;152(4 Pt 1):13911394.

35. Rau JL, Harwood RJ, Groff JL. Evaluation of a reservoir device for metered-dose bronchodilator delivery to intubated adults: an invitro study. Chest 1992;102(3):924-930.

36. Morén F, Anderson J. Fraction of dose exhaled after administration of pressurized inhalation aerosols. Int J Pharm 1980;6(3-4):295-300.

37. Goode ML, Fink JB, Dhand R, Tobin MJ. Improvement in aerosol delivery with helium-oxygen mixtures during mechanical ventilation. Am J Respir Crit Care Med 2001;163(1):109-114.

38. O'Doherty MJ, Thomas SH, Page CJ, Treacher DF, Nunan TO. Delivery of a nebulized aerosol to a lung model during mechanical ventilation. Effect of ventilator settings and nebulizer type, position, and volume of fill. Am Rev Respir Dis 1992;146(2):383-388.

39. Thomas SH, O'Doherty MJ, Page CJ, Treacher DF, Nunan TO. Delivery of ultrasonic nebulized aerosols to a lung model during mechanical ventilation. Am Rev Resp Dis 1993;148(4):872-877.

40. Thomas SH, O'Doherty MJ, Fidler HM, Page CJ, Treacher DF, Nunan TO. Pulmonary deposition of a nebulised aerosol during mechanical ventilation. Thorax 1993;48(2):154-159.

41. Hess DR, Fisher D, Williams P, Pooler S, Kacmarek RM. Medication nebulizer performance. Effects of diluent volume, nebulizer flow, and nebulizer brand. Chest 1996;110(2):498-505.

42. Harvey CJ, O'Doherty MJ, Page CJ, Thomas SH, Nunan TO, Treacher DF. Effect of a spacer on pulmonary aerosol deposition from a jet nebulizer during mechanical ventilation. Thorax 1995; 50(1):50-53

43. Newman SP. How well do in vitro particle size measurements predict drug delivery in vivo? J Aerosol Med 1998;11(Suppl 1): S97-104.

44. Dhand R, Sohal H. Pulmonary drug delivery system for inhalation therapy in mechanically ventilated patients. Expert Rev Med Devices 2008;5(1):9-18.

45. Waldrep JC, Berlinski A, Dhand R. Comparative analysis of methods to measure aerosols generated by a vibrating mesh nebulizer. J Aerosol Med 2007;20(3):310-319.

46. Van Dyke RE, Nikander K. Delivery of iloprost inhalation solution with the HaloLite, Prodose, and I-neb adaptive aerosol delivery systems: an in vitro study. Respir Care 2007;52(2):184-190.

47. Polli GP, Grim WM, Bacher FA, Yunker MH. Influence of formulation on aerosol particle size. J Pharm Sci 1969;58(4):484-486.

48. Kim CS, Trujillo D, Sackner MA. Size aspects of metered-dose inhaler aerosols. Am Rev Respir Dis 1985;132(1):137-142.

49. Ehrmann S, Roche-Campo F, Sferrazza Papa GF, Isabey D, Brochard L, Apiou-Sbirlea G. Aerosol therapy during mechanical ventilation: an international survey. Intensive Care Med 2013;39(6): 1048-1056.
50. MacNeish CF, Meisner D, Thibert R, Kelemen S, Vadas EB, Coates AL. A comparison of pulmonary availability between Ventolin (albuterol) nebules and Ventolin (albuterol) respirator solution. Chest 1997;111(1):204-208.

51. Berlinski A, Waldrep JC. Nebulized drug admixtures: effect on aerosol characteristics and albuterol output. J Aerosol Med 2006; 19(4):484-490.

52. Coates AL, MacNeish CF, Meisner D, Kelemen S, Thibert R, MacDonald J, Vadas E. The choice of jet nebulizer, nebulizing flow, and addition of albuterol affects the output of tobramycin aerosols. Chest 1997;111(5):1206-1212.

53. Flament MP, Leterme P, Burnouf T, Gayot A. Influence of formulation on jet nebulisation quality of $\alpha_{1}$ protease inhibitor. Int J Pharm 1999;178(1):101-109.

54. Lee TY, Chen CM, Lee CN, Chiang YC, Chen HY. Compatibility and osmolality of inhaled $\mathrm{N}$-acetylcysteine nebulizing solution with fenoterol and ipratropium. Am J Health Syst Pharm 2005;62(8): 828-833.

55. Joseph JC. Compatibility of nebulizer solution admixtures. Ann Pharmacother 1997;31(4):487-489.

56. Kamin W, Schwabe A, Krämer I. Inhalation solutions: which ones are allowed to be mixed? Physico-chemical compatibility of drug solutions in nebulizers. J Cyst Fibros 2006;5(4):205-213.

57. McKenzie JE, Cruz-Rivera M. Compatibility of budesonide inhalation suspension with four nebulizing solutions. Ann Pharmacother 2004;38(6):967-972.

58. Alvine GF, Rodgers P, Fitzsimmons KM, Ahrens RC. Disposable jet nebulizers. How reliable are they? Chest 1992;101(2):316-319.

59. Loffert DT, Ikle D, Nelson HS. A comparison of commercial jet nebulizers. Chest 1994;106(6):1788-1792.

60. Terzano C, Petroianni A, Parola D, Ricci A. Compressor/nebulizer differences in the nebulization of corticosteroids. The CODE study (Corticosteroids and Devices Efficiency). Eur Rev Med Pharmacol Sci 2007;11(4):225-237.

61. Waldrep JC, Keyhani K, Black M, Knight V. Operating characteristics of 18 different continuous-flow jet nebulizers with beclomethasone dipropionate liposome aerosol. Chest 1994;105(1):106-110.

62. Craven DE, Goularte TA, Make BJ. Contaminated condensate in mechanical ventilator circuits: a risk factor for nosocomial pneumonia. Am Rev Respir Dis 1984;129(4):625-628.

63. Beaty CD, Ritz RH, Benson MS. Continuous in-line nebulizers complicate pressure support ventilation. Chest 1989;96(6):13601363.

64. Phillips GD, Millard FJ. The therapeutic use of ultrasonic nebulizers in acute asthma. Respir Med 1994;88(5):387-389.

65. Dhand R, Guntur VP. How best to deliver aerosol medications to mechanically ventilated patients. Clin Chest Med 2008;29(2):277296.

66. Dhand R. Aerosol delivery during mechanical ventilation: from basic techniques to new devices. J Aerosol Med Pulm Drug Deliv 2008;21(1):45-60.

67. Waldrep JC, Dhand R. Advanced nebulizer designs employing vibrating mesh/aperture plate technologies for aerosol generation. Curr Drug Deliv 2008;5(2):114-119.

68. Hurley PK, Smye SW, Cunliffe H. Assessment of antibiotic aerosol generation using commercial jet nebulizers. J Aerosol Med 1994; 7(3):217-228.

69. Dhand R. Aerosol therapy during mechanical ventilation: getting ready for prime time. Am J Respir Crit Care Med 2003;168(10): 1148-1149.

70. Miller DD, Amin MM, Palmer LB, Shah AR, Smaldone GC. Aerosol delivery and modern mechanical ventilation: in vitro/in vivo evaluation. Am J Respir Crit Care Med 2003;168(10):1205-1209. 


\section{Aerosol Therapy in Pulmonary Critical Care}

71. Hughes J, Saez J. Effects of nebulizer mode and position in a mechanical ventilator circuit on dose efficiency. Respir Care 1987; 32(12):1131-1135.

72. Sidler-Moix AL, Dolci U, Berger-Gryllaki M, Pannatier A, Cotting J, Di Paolo ER. Albuterol delivery in an in vitro pediatric ventilator lung model: comparison of jet, ultrasonic and mesh nebulizers. Pediatr Crit Care Med 2013;14(2):e98-e102.

73. Wan GH, Lin HL, Fink JB, Chen YH, Wang WJ, Chiu YC, et al. In vitro evaluation of aerosol delivery by different nebulization modes in pediatric and mechanical ventilator modes. Respir Care 2014;59(10):1494-1500.

74. Berlinski A, Willis JR. Albuterol delivery by 4 different nebulizers placed in 4 different positions in a pediatric ventilator in vitro model. Respir Care 2013;58(7):1124-1133.

75. Moraine JJ, Truflandier K, Vandenbergen N, Berré J, Mélot C, Vincent JL. Placement of the nebulizer before the humidifier during mechanical ventilation: Effect on aerosol delivery. Heart Lung 2009; 38(5):435-439.

76. Fink J. Metered-dose inhalers, dry powder inhalers and transitions. Respir Care 2000;45(6):623-635.

77. Everard ML, Devadason SG, Summers QA, Le Souëf PN. Factors affecting total and "respirable" dose delivered by a salbutamol metered dose inhaler. Thorax 1995;50(7):746-749.

78. O'Callaghan C, Lynch J, Cant M, Robertson C. Improvement in sodium cromoglycate delivery from a spacer device by use of an antistatic lining, immediate inhalation, and avoiding multiple actuations of drug. Thorax 1993;48(6):603-606.

79. Barry PW, O'Callaghan C. The effect of delay, multiple actuations and spacer static charge on the in vitro delivery of budesonide from the Nebuhaler. Br J Clin Pharmacol 1995;40(1):76-78.

80. Clark DJ, Lipworth BJ. Effect of multiple actuations, delayed inhalation and antistatic treatment on the lung bioavailability of salbutamol via a spacer device. Thorax 1996;51(10):981-984.

81. Rau JL, Zhu Y. Reservoir design and dose availability with longterm metered dose inhaler corticosteroid use. J Aerosol Med 1998; 11(1):15-26.

82. Bishop MJ, Larson RP, Buschman DL. Metered dose inhaler aerosol characteristics are affected by the endotracheal tube actuator/adapter used. Anesthesiology 1990;73(6):1263-1265.

83. Williams RO 3rd, Patel AM, Barron MK, Rogers TL. Investigation of some commercially available spacer devices for the delivery of glucocorticoid steroids from a pMDI. Drug Dev Ind Pharm 2001; 27(5):401-412

84. Fuller HD, Dolovich MB, Turpie FH, Newhouse MT. Efficiency of bronchodilator aerosol delivery to the lungs from the metered dose inhaler in mechanically ventilated patients. A study comparing four different actuator devices. Chest 1994;105(1):214-218.

85. Dhand R, Duarte AG, Jubran A, Jenne JW, Fink JB, Fahey PJ, Tobin MJ. Dose response to bronchodilator delivered by metereddose inhaler in ventilator supported patients. Am J Respir Crit Care Med 1996;154(2):388-393.

86. Dhand R, Tobin MJ. Bronchodilator delivery with metered-dose inhalers in mechanically-ventilated patients. Eur Respir J 1996; 9(3):585-595.

87. O'Riordan TG, Palmer LB, Smaldone GC. Aerosol deposition in mechanically ventilated patients. Optimizing nebulizer delivery. Am J Respir Crit Care Med 1994;149(1):214-219.

88. Guerin C, Fassier T, Bayle F, Lemasson S, Richard JC. Inhaled bronchodilator administration during mechanical ventilation: how to optimize it and for which clinical benefit? J Aerosol Med Pulm Drug Deliv 2008;21(1):85-96.

89. Hess DR, Dillman C, Kacmarek RM. In vitro evaluation of aerosol bronchodilator delivery during mechanical ventilation: pressurecontrol vs. volume control ventilation. Intensive Care Med 2003; 29(7):1145-1150.

90. Andersen JB, Klausen NO. A new mode of administration of nebulized bronchodilator in severe bronchospasm. Eur J Respir Dis Suppl 1982;119:97-100.

91. Fink JB, Tobin MJ, Dhand R. Bronchodilator therapy in mechanically ventilated patients. Respir Care 1999;44(1):53-69.

92. Crogan SJ, Bishop MJ. Delivery efficiency of metered dose aerosols given via endotracheal tubes. Anesthesiology 1989;70(6):10081010.

93. Garner SS, Wiest DB, Bradley JW. Albuterol delivery by metereddose inhaler with a pediatric mechanical ventilatory circuit model. Pharmacotherapy 1994;14(2):210-214.

94. Ryan SN, Rankin N, Meyer E, Williams R. Energy balance in the intubated human airway is an indicator of optimal gas conditioning. Crit Care Med 2002;30(2):355-361.

95. Schulze A. Respiratory gas conditioning in infants with an artificial airway. Semin Neonatol 2002;7(5):369-377.

96. Lange CF, Finlay WH. Overcoming the adverse effect of humidity in aerosol delivery via pressurized metered-dose inhalers during mechanical ventilation. Am J Respir Crit Care Med 2000;161(5):1614-1618.

97. Lin HL, Fink JB, Zhou Y, Cheng YS. Influence of moisture accumulation in inline spacer on delivery of aerosol using metered-dose inhaler during mechanical ventilation. Respir Care 2009;54(10):13361341.

98. Bowers W. Effects of heat and moisture exchangers designed to allow aerosol delivery on aerosol deposition in simulated mechanically ventilated adults. Atlanta, GA: Georgia State University; 2010.

99. Svartengren M, Anderson M, Philipson K, Camner P. Human lung deposition of particles suspended in air or in helium/oxygen mixture. Exp Lung Res 1989;15(4):575-585.

100. Ari A, Fink J. Aerosol drug delivery administration with heliumoxygen (heliox) mixtures: an overview. Curr Respir Med Rev 2010; 6(2):80-85.

101. Duarte AG. Inhaled bronchodilator administration during mechanical ventilation. Respir Care 2004;49(6):623-634.

102. Tassaux D, Jolliet P, Thouret JM, Roeseler J, Dorne R, Chevrolet JC. Calibration of seven ICU ventilators for mechanical ventilation with helium-oxygen mixtures. Am J Respir Crit Care Med 1999; 160(1):22-32.

103. Takaya T, Takeyama K, Takiguchi M. The efficiency of $\beta_{2}$-agonist delivery through tracheal tubes with the metered-dose inhaler: an in vitro study. J Anesth 2002;16(4):284-288.

104. Ahrens RC, Ries RA, Popendorf W, Wiese JA. The delivery of therapeutic aerosols through endotracheal tubes. Pediatr Pulmonol 1986;2(1):19-26.

105. O'Riordan TG, Greco MJ, Perry RJ, Smaldone GC. Nebulizer function during mechanical ventilation. Am Rev Respir Dis 1992;145(5): 1117-1122.

106. Piccuito CM, Hess DR. Albuterol delivery via tracheostomy tube. Respir Care 2005;50(8):1071-1076.

107. Ari A, Harwood RJ, Sheard MM, Fink JB. An in vitro evaluation of aerosol delivery through tracheostomy and endotracheal tubes using different interfaces. Respir Care 2012;57(7):1066-1070. 
108. Berlinski A. Nebulized albuterol delivery in a model of spontaneously breathing children with tracheostomy. Respir Care 2013; 58(12):2076-2086.

109. Berlinski A, Chavez A. Albuterol delivery via metered dose inhaler in a spontaneously breathing pediatric tracheostomy model. Pediatr Pulmonol 2013;48(10):1026-1034.

110. Mirza S, Hopkinson L, Malik TH, Willatt DJ. The use of inhalers in patients with tracheal stomas or tracheostomy tubes. J Laryngol Otol 1999;113(8):762-764.

111. Nakhla V. A homemade modification of a spacer device for delivery of bronchodilator or steroid therapy in patients with tracheostomies. J Laryngol Otol 1997;111(4):363-365.

112. Parkes SN, Bersten AD. Aerosol kinetics and bronchodilator efficacy during continuous positive airway pressure delivered by face mask. Thorax 1997;52(2):171-175.

113. MacIntyre N. Aerosol delivery through an artificial airway. Respir Care 2002;47(11):1279-1285; discussion 1285-1289.

114. Dhand R. Special problems in aerosol delivery: artificial airways. Respir Care 2000;45(6):636-645.

115. Pitance L, Vecellio L, Delval G, Reychler G, Reychler H, Liistro G. Aerosol delivery through tracheostomy tubes: an in vitro study. J Aerosol Med Pulm Drug Deliv 2013;26(2):76-83.

116. Dolovich MB, Ahrens RC, Hess DR, Anderson P, Dhand R, Rau JL, et al. Device selection and outcomes of aerosol therapy: evidencebased guidelines: American College of Chest Physicians/American College of Asthma, Allergy, and Immunology. Chest 2005;127(1): 335-371.

117. Laube BL, Janssens HM, de Jongh FH, Devadason SG, Dhand R, Diot $\mathrm{P}$, et al. What the pulmonary specialist should know about the new inhalation therapies. Eur Respir J 2011;37(6):1308-1331.
118. Marik P, Hogan J, Krikorian J. A comparison of bronchodilator therapy delivered by nebulization and metered-dose inhaler in mechanically ventilated patients. Chest 1999;115(6):1653-1657.

119. Ely EW, Baker AM, Evans GW, Haponik EF. The distribution of costs of care in mechanically ventilated patients with chronic obstructive pulmonary disease. Crit Care Med 2000;28(2):408-413.

120. Dhand R. Inhalation therapy in invasive and noninvasive mechanical ventilation. Curr Opin Crit Care 2007;13(1):27-38.

121. Dhand R. Inhalation therapy with metered-dose inhalers and dry powder inhalers in mechanically ventilated patients. Respir Care 2005;50(10):1331-1334; discussion 1344-1345.

122. Duarte AG, Momii K, Bidani A. Bronchodilator therapy with metered dose inhaler and spacer versus nebulizer in mechanically ventilated patients: comparison of magnitude and duration of response. Respir Care 2000;45(7):817-823.

123. Chang LH, Honiden S, Haithcock JA, Das AM, Short KA, Nierman DM, Carson SS. Utilization of bronchodilators in ventilated patients without obstructive airways disease. Respir Care 2007;52(2): 154-158.

124. Craven DE, Lichtenberg DA, Goularte TA, Make BJ, McCabe WR. Contaminated medication nebulizers in mechanical ventilator circuits. Source of bacterial aerosols. Am J Med 1984;77(5):834-838.

125. Hamill RJ, Houston ED, Georghiou PR, Wright CE, Koza MA, Cadle RM, et al. An outbreak of Burkholderia cepacia respiratory tract colonization and infection associated with nebulized albuterol therapy. Ann Intern Med 1995;122(10):762-766.

126. Hamill RJ, Houston ED, Georghiou PR, Wright CE, Koza MA, Cadle RM, et al. Respiratory tract colonization and infection associated with nebulized albuterol therapy. Ann Intern Med 1995; 122(10):762-766.

\section{Discussion}

DiBlasi: I want to thank you for doing a lot of the initial work with many of the new aerosol delivery devices in conjunction with mechanical ventilation; this research has definitely guided our practice in the ICU. You mentioned placing the nebulizer back before the humidifier, and I think that practice is now widespread thanks to your research. We were doing that for quite a while in our ICU, and we were using a ventilator that had a slightly lower bias flow. Like all devices that come into our institution, we went on to test the delivery of albuterol using a newer ventilator that uses, especially in the neonatal mode, a bias flow of around $6 \mathrm{~L} / \mathrm{min}$, and we found that there was hardly any drug being delivered to the filter, whereas before, there was a significant amount of drug provided at lower bias flows. You've established drug delivery in the pediatric and adult populations, at least on a lung model, but I think we need to look a little bit closer at the neonatal population because what I'm finding is that you get greater drug delivery when you place the nebulizer up the inspiratory limb closer to the patient Y-piece. I think a lot of this has to do with the fact that the bolus of drug that's being emitted into the circuit, due to the low inspiratory times and the high breathing frequency, may take 3 or 4 breaths to reach the patient, and in that time, a lot is being flushed out into the expiratory limb. So there's negligible drug being delivered to an infant lung model. I think it's important for people to realize that we may not necessarily be able to extrapolate from those adult and pediatric data and expect that we're going to have similar effects in neonates. I think it would be wonderful for all of us to come together at some point and agree that we realize that aerosol delivery devices are more efficient, but what about the ventilator you're using? With identical settings, what is the delivery like between different ventilator types? I think it's important that we develop tables for adult, neonatal, and pediatric populations using all of these available devices to really find what the best solution is for aerosol delivery.

Ari: First, thanks so much for your kind thoughts about our previous research. The work that I presented today is based on the adult and pediatric in vitro studies that were conducted in our research lab at Georgia State University (GSU). The findings of our studies with the adult and pediatric lung models may not be applicable to neonates. I am also familiar with your study on nebulizer placement using an infant lung model that you presented at the AARC Congress 2 years ago. We all know that aerosol delivery to adults, pediatrics, and neonates may differ significantly; therefore, clinical research is warranted for us to understand differences in aerosol drug delivery to different patient populations. I also agree with you about preparing a table or a guideline that will help 
educate clinicians on the best way to deliver aerosolized drugs to adult, pediatric, and neonatal populations.

Berlinski: Thank you for the nice review. I want to comment about 2 things. First, you did not discuss pMDI adapters that require removal of the canister from the manufacturer's actuator and placement in a universal actuator/nozzle. At least in our hands, in agreement with previously published data, they're extremely inefficient, so I'd like to know your opinion on that. Second, I would like to challenge the notion that increasing $V_{T}$ positively affects drug delivery. I think the only data I've seen published is from Jim Fink, ${ }^{1}$ but that was with CPAP. In the pediatric range (100$300 \mathrm{~mL}$ ), we do not see any benefit. There's an adult study from a Greek group $^{2}$ that publishes a lot on COPD that went from 8 to $12 \mathrm{~mL} / \mathrm{kg}$ - don't quote me on the exact number-but with a significant increase in $\mathrm{V}_{\mathrm{T}}$. They did not see a difference in outcome, and if I remember correctly, they were measuring airway resistance. So I think that we probably need to revisit the notion that increasing $\mathrm{V}_{\mathrm{T}}$ is crucial to delivery.

* Fink: The articles we published did not say the bigger the volume, the better the delivery; we said that there are some low $\mathrm{V}_{\mathrm{T}}$ limits at which the delivery might fall off. That's different than saying you should go from 4 or $5 \mathrm{~mL} / \mathrm{kg}$ up to 20 or $30 \mathrm{~mL} / \mathrm{kg}$ to get more aerosol into your patients. What we did say was that with no bias flow, if you have a volume that's less than the volume in the circuit between the nebulizer to the patient, it could reduce delivery, and that was with a pMDI for that particular study. So I totally agree with you that bigger isn't better in terms of volume in aerosol delivery, but in the study Rob [DiBlasi] did with neonates, where you have 150 or $200 \mathrm{~mL}$ of tubing and a half-liter of flow going through it, it can take you 5-10 breaths to get that bolus of aero- sol to the patient airway if it's back at the ventilator. Bigger volumes may have an effect in the neonatal realm that's more obvious than what it might potentially be for adults or even pediatrics. That speaks to your issue that we need to catalogue a whole range of different systems that we have out there because I get calls every day from therapists saying, "give me a simple answer-where should I put this nebulizer?" Well, you need to know what vent you're using, what's your bias flow, and what your conditions are. It's not a simple one-answer-fitsall, and if it were, we wouldn't need respiratory therapists (RTs) to be trained in ventilation and aerosols. The academic community can help by getting this characterization for us with neonates, pediatrics, and adults.

$\uparrow$ MacIntyre: I get very confused on this issue despite the fact that you all write this wonderful stuff. What if you had no bias flow_- does this make sense? Since the best place to put your aerosols is at the beginning of the breath, the front part of your breath, wouldn't it make more sense to bring your nebulizer down closer to the Ypiece? You want some charging volume if it's continuous.

* Fink: I think I got it. With no bias flow, yes, it's good to put it closer to the patient, but if you have it too close, like right on the Y-piece, and you give something that's a bolus like ultrasonic or vibrating mesh, as you fire the ventilator before you start pushing air into the patient, you fill the expiratory limb with compressible volume. This means that you might lose one third to one half of that bolus. That's one reason that some bias flow going back to the ventilator may actually increase delivery. In the case of Arzu's paper, ${ }^{3}$ it went from $17 \%$ to up to $27 \%$.

$\uparrow$ MacIntyre: I guess the point I was making is you make these sort of blanket recommendations; there's only one sentence for placement of the nebu- lizer, which was closest to the vent. And what I'm trying to get straight in my brain...

Ari: In my presentation, I made a suggestion on the placement of jet nebulizers during mechanical ventilation. As I said earlier, aerosol delivery via jet nebulizers was greater when they were placed close to the ventilator.

$†$ MacIntyre: Okay, it wasn't clear to me that it was a jet nebulizer. But if it's a non-jet nebulizer and there's no bias flow, then that recommendation doesn't hold true.

Ari: Exactly! In one of our studies, we found that aerosol drug delivery with pMDIs and mesh and ultrasonic nebulizers was greater when they were attached to the Y-adapter. I also talked about it during my presentation today.

* Fink: Just a quick point regarding these nebulizers and different placements and what the efficiency is - the efficiency isn't the issue. The issue is how much drug do you want to get into the patient. Neil, your article in 1985 where you had $3 \%$ on the vent and $12 \%$ with the same nebulizer off the vent is so critical because, as Arzu mentioned earlier, all of our drugs approved for inhalation aren't for very sick patients at home. So if you're going to give a drug for which the dose matters, which isn't true of albuterol or maybe ipratropium, but is for everything else (such as antibiotics, mucokinetics, and anti-inflammatory agents), you want to make sure that you have the same lung dose on the ventilator as off the ventilator to get an effect.

Hill: I wonder if you could clarify one thing for me. I thought I heard you say that volume-limited has some advantages compared with pressurelimited ventilation. I'm surprised that you could make that kind of blanket statement because I would think, especially based on the discussion just 
now, that it depends on a lot of factors.

Ari: The point that I was trying to make during my presentation is that aerosol delivery during mechanical ventilation is dependent upon many factors. One of the factors we may need to consider is ventilator mode used during aerosol therapy in ventilator-dependent patients. Dr Hess conducted a study in $2003^{4}$ to evaluate delivery of albuterol from a pMDI and jet nebulizer in 2 different ventilator modes, including volume control ventilation and pressure control ventilation. The findings of his study showed that aerosol delivery by a pMDI was the same regardless of which ventilator mode, inspiratory time, and ventilator settings were used. However, the efficiency of nebulizers differed across conditions tested in his study. Dr Hess may want to talk about the findings of his study for us.

Hess: When the nebulizer was used in our study, there was a complex interaction between aerosol delivery with flow pattern, inspiratory time, and simulated lung mechanics. With use of a pMDI, the flow pattern didn't matter much because the dose was frontloaded.

$\uparrow$ MacIntyre: Arzu, didn't you just quote Jim Fink that descending flow patterns were better? Did I miss something?

Hess: I don't think that was necessarily the case.

$\uparrow$ MacIntyre: So the square one was better?

Ari: No, as I mentioned in my presentation, the square waveform has lower aerosol deposition than the descending flow waveform during mechanical ventilation. $\uparrow$ MacIntyre: Is it fair to say that you can't make blanket recommendations? There are so many variables in play here that I'm not sure that a simple one-sentence statement can be made.

Hess: I will agree with that; I was going to raise my hand earlier to make the point that outside of where you place the device in the circuit, I'm not convinced that we should be messing with the ventilator settings while we're delivering aerosolized drugs because there are so many competing factors. Let's assume that with a larger $\mathrm{V}_{\mathrm{T}}$, you will deliver more drug, but you injure the lung by doing that. Lower flow delivers more drug, but it prolongs the inspiratory phase, and you get more air trapping. Dry gas delivers more drug, but it dries out the endotracheal tube. Having done some work in this area, I don't think the added benefit and the potential risks warrant changing the ventilator settings.

* Fink: So why do we need this information?

Hess: Good question. I think that if we were doing a dosing study for a new drug, maybe it's important that it's all done the same way. Or maybe not because in the real world, people are just going to put the nebulizer where they want.

* Fink: This goes to what you talked about with high-flow nasal cannula. We know when we're at 10 versus 30 versus $60 \mathrm{~L} / \mathrm{min}$, the inhaled dose is very different. One of the important things about this type of discussion to my mind is that you don't change the person to fit the suit; you change the suit to fit the person. So you adjust the administered dose to deliver the effective dose to the lungs in light of the parameters, systems, and patient conditions that you're treating. You can control the types of aerosol generator, but for those other issues, like the flow you're ventilating with, you should understand the implications of what you're doing to the patient and what you should be dosing.

Hess: If you're delivering albuterol, which is probably the most commonly delivered aerosolized drug during mechanical ventilation, and you're trying to maximize the amount that goes into the lung, albuterol solution is cheap, so just double the dose instead of messing around with all these different factors.

DiBlasi: I'd like to add to that. Arzu showed very nicely that the residual volume of the most common nebulizer that we're currently using during mechanical ventilation is about $0.2 \mathrm{~mL}$. So why are we diluting our albuterol with normal saline? Why can't we give pure drug or add the 0.2 extra to that and get maximum efficiency or somewhere close to what we would like to have? Is there a reason we dilute albuterol?

Ari: According to Dr Hess' study that was published in 1996, 5 increasing fill volume with jet nebulizers improves delivery efficiency of the nebulizer. Dr Hess may want to comment on that.

Hess: In my study, we were looking at jet nebulizers, and I think Rob is referring to a mesh nebulizer. And I don't use the multi-dose bottles anymore; I use the unit doses and just squirt the whole thing in. Particularly with the mesh nebulizer, that's just fine.

Ari: Yes, my comment was on jet nebulizers, not mesh nebulizers. I also believe that using the standard unit dose with mesh nebulizers should be fine. We don't need to increase the fill volume of the mesh nebulizer to increase delivery efficiency of the nebulizer. Unlike jet nebulizers, mesh nebulizers have a very small residual volume. Therefore, they are efficient 
in aerosol drug delivery without increasing the fill volume by diluting albuterol with saline.

Berlinski: Ijust want to make a comment about Dean's statement that shows you cannot make blanket statements. If you apply your theory of not messing with the ventilator, you have to say that is for adults because if you're working in pediatrics, and your $\mathrm{V}_{\mathrm{T}}$ is $50 \mathrm{~mL}$, and you put $8 \mathrm{~L} / \mathrm{min}$ on a nebulizer, you'll have to turn the set $\mathrm{V}_{\mathrm{T}}$ to almost zero volume...

Hess: Or use a mesh nebulizer.

Berlinski: That's right, but not everybody has access to that technology. I agree that that's the only condition where you need to modify the ventilator parameters so you don't harm your patient. There also are issues associated with cost that have not been part of the discussion here. When we published our study, one of the reviewers came back and said, "show me how much this is going to cost." For a drug like albuterol, is it worth it? So we had to go back and calculate for 1, 7, and 28 days of use whether it was worth using that very expensive technology to deliver albuterol as opposed to using an inexpensive lowvolume nebulizer. ${ }^{6}$ You don't need a super-efficient nebulizer for every single situation. I think it's important that we have great devices to deliver very specific drugs, but for albuterol, we can get by with using an inefficient device with 2 doses instead of one at very low cost.

Hess: Actually, your point about $\mathrm{V}_{\mathrm{T}}$ augmentation with a jet nebulizer is, I would argue, just as important in adults as it is in pediatrics because we now use much lower $\mathrm{V}_{\mathrm{T}}$ in adults. I think a common error that's made in everyday practice is to not consider that with use of a jet nebulizer. The other thing that I don't think you mentioned is that with a jet nebulizer, it can significantly impact the patient's ability to trigger the ventilator, which can be an issue in patients who have autoPEEP and obstructive lung disease. They have difficulty triggering to begin with, and then you add that additional bias flow and make it even more difficult to trigger the ventilator. There's at least one study ${ }^{7}$ in the literature showing subjects on pressure support who did not trigger when the nebulizer flow was added into the vent circuit. We converted just within the last year to mesh nebulizers, and it was to get around some of these issues.

Rubin: I'm impressed by the astounding number of high-quality bench studies looking at different ventilation modes, patient sizes, depositions, nebulizers, and aerosol devices - the data are remarkable. What's entirely unimpressive are the lack of data showing that these medications are worth a damn to most of the patients we give them to in the ICU. Whether it's inhaled steroids, albuterol, or dornase, we give loads of nebulized medication, and there are very few data suggesting that they are of any benefit at all.

$\uparrow$ MacIntyre: The ARDSNet got off on a tangent and thought that pushing albuterol in patients with ARDS might help lung water clearance. It was a study $^{8}$ that was unfortunately sort of ill-designed because the goal was to put enough albuterol in the lungs to do this, and most of the investigators were reluctant to push the dose to the levels that might have had an effect on lung water clearance. So we ended up under-dosing these patients, finding no effect (not that you could guarantee an effect even if we had dosed properly), and at the end of the day, we came away with the conclusion that the albuterol really did nothing.

Hill: There may be a very good reason why this isn't listed anywhere, and it may be out of bounds, but did you want to comment at all on high-fre- quency oscillatory ventilation (HFOV) and aerosols?

Ari: Well, we conducted a study on aerosol delivery during HFOV. ${ }^{9}$ It was one of our student's thesis. I know that Rob conducted another study on this after our project was completed and published as an abstract. I would like to give him a chance to describe his study before explaining the study we conducted at GSU.

DiBlasi: We attempted to enroll a number of patients in a clinical trial a few years back to evaluate the success of weaning from inhaled nitric oxide using iloprost. At the time, we were going to use the Aerogen nebulizer, and we did not enroll one patient. The main reason was that they were being supported by HFOV, and nobody in their right mind at the time would have considered giving an inhaled drug through an oscillator simply because there are high turbulent flows, fast rates, and very low $\mathrm{V}_{\mathrm{T}}$. So I took the question back to the bench, and we evaluated drug delivery in a neonatal lung model, and we've since done it in pediatric and adult lung models. We compared efficiency and drug delivery between different placements within the circuit using conventional ventilation and HFOV, and I was very amazed to find that, in all these studies, there was a nearly 2-3-fold increase in drug delivery in neonatal and pediatric models but not adult models during HFOV. I think a lot of it has to do with the higher rate, potentially the smoother bore tubing. I can't quite exactly put my finger on it, but every single study we've done (except adult) comparing conventional ventilation and HFOV, HFOV provided much more drug, and it really does depend on circuit placement. Placing the nebulizer proximal to the airway resulted in, I think, a 3-fold greater increase in drug delivery. With it placed between the ventilator and humidifier, the drug delivery was negligible. So now we feel more comfortable providing that 
drug to our patients who are receiving HFOV.

Ari: One of our graduate students compared aerosol delivery difference between conventional mechanical ventilation and HFOV using a ventilator-dependent adult lung model. ${ }^{9}$ The findings of his thesis showed that albuterol deposition with a pMDI was more than 2 times greater with HFOV than with conventional mechanical ventilation. We also determined the effect of lung compliance on aerosol delivery and found that lung compliance and aerosol delivery are directly related. Increasing lung compliance from 20 to $40 \mathrm{~mL} / \mathrm{cm} \mathrm{H}_{2} \mathrm{O}$ increased aerosol delivery during conventional mechanical ventilation and HFOV. Changing lung compliance had an almost 2-fold impact on aerosol delivery during both modes of ventilation. I would also like to ask Jim if he wants to comment on that because he worked with us on this project.

* Fink: We used a bi-directional adapter right on the ETT and heated humidity, and we compared that to conventional ventilation, and we found that instead of the $15 \%$ or $17 \%$ we expected from conventional ventilation as found in our previous work, we delivered 30\%. And I think the point of the study wasn't so much how to deliver albuterol-we used albuterol because it was there and ready-but that you can get up to $30 \%$ of drug into an adult during HFOV with a pMDI (or any aerosol device) when everyone thought you couldn't get it in. Now if we actually had drugs that made a difference in a pMDI, to $\mathrm{Dr}$ Rubin's point, then this type of information really helps to know whether we should be doing it or not. If you are giving aerosol during HFOV, you can deliver a lot of aerosol, but you just need to position the pMDI between the circuit and the patient, not back at the humidifier.
DiBlasi: I wonder if the mechanism through which more drug is delivered to the lung model may have something to do with the active exhalation? Drug is being placed into the expiratory limb, but the piston's moving backward, so could that drug be dispersed closer to the airway so that the bolus on inhalation is twice as large rather than being rinsed out through the expiratory limb?

Restrepo: We have a room full of experts, but how about if you're starting out in an ICU, you need to buy equipment, and you need to invest and find out from a practical purpose, which device do you use and how do you tell RTs to use it tomorrow? What would your answer be?

Ari: Well, that's a great question, and its answer is a little complicated due to all the factors that influence aerosol delivery during mechanical ventilation and characteristics of aerosol devices on the market. The decision should be based on the type of patients you will be treating in your unit, the type of drugs, and the doses you need to use for treatment. Also, I hesitate to say choose this device over another because I would like to keep my reputation as an unbiased scholar.

Hess: I'll stick my neck out. I would buy ventilators that have a mesh nebulizer-powering unit built into the ventilator. And I would also have very clear guidelines as to when inhaled drugs should be used during mechanical ventilation because I think they're overused.

Restrepo: How would you use albuterol? Albuterol is the thing that every single patient with pneumonia- or anyone else-gets in an ICU. What would you recommend?

Hess: That would point to the guidelines I talked about. Why would you use albuterol in a patient with pneu- monia? But that's another discussion. The other issue that has come up that we touched on a little but did not talk about a lot is that the HFA formulations of albuterol are much more expensive than the generic CFC albuterol inhalers of a few years ago. Many pharmacies and hospitals have pushed respiratory care departments not to use pMDIs because it turns out that using the solution, even with a more expensive nebulizer like the mesh nebulizer, is cost-effective over time.

* Fink: As an alternative view, my message is that if I don't have access to the mesh, which many clinicians around the world don't at this point in time, I need to know what dose can get into the lungs with the technology I have available. We need to adjust dosing to fit the technology and conditions to get a target dose that is going to be effective, which is very important with antibiotics, but probably not so much with albuterol. Alex Duarte did a study ${ }^{10}$ a number of years ago in RESPIRATORY CARE comparing 4 puffs with a pMDI with a standard albuterol dose in stable COPD subjects: they all got bronchodilation, and they all had about the same duration of effect.

Ari: Thank you very much for all your comments, suggestions, and questions about aerosol drug delivery in critical pulmonary care. Although I would like to hear more of your thoughts on this important topic, I am afraid we must now move on from this discussion and continue with the next speaker. Thank you!

* James B Fink PhD RRT FAARC, James B Fink LLC, San Mateo, California, and Division of Respiratory Therapy, Georgia State University, Atlanta, Georgia, representing Aerogen.

$\dagger$ Neil R MacIntyre MD FAARC, Division of Pulmonary and Critical Care Medicine, Duke University, Durham, North Carolina, representing InspiRx. 


\section{Aerosol Therapy in Pulmonary Critical Care}

\section{REFERENCES}

1. Fink JB, Dhand R, Duarte AG, Jenne JW, Tobin MJ. Aerosol delivery from a metered-dose inhaler during mechanical ventilation: an in-vitro model. Am J Respir Crit Care Med 1996;154(2 Pt 1):382-387.

2. Mouloudi E, Katsanoulas K, Anastasaki M, Hoing S, Georgopoulos D. Bronchodilator delivery by metered-dose inhaler in mechanically ventilated COPD patients: influence of tidal volume. Intensive Care Med 1999;25(11):1215-1221.

3. Ari A, Areabi H, Fink JB. Evaluation of aerosol generators at 3 locations in humidified and nonhumidified circuits during adult mechanical ventilation. Respir Care 2010;55(7):837-844.
4. Hess DR, Dillman C, Kacmarek RM. In vitro evaluation of aerosol bronchodilator delivery during mechanical ventilation: pressure-control vs volume-control ventilation. Intensive Care Med 2003;29(7): 1145-1150.

5. Hess DR, Fisher D, Williams P, Pooler S, Kacmarek RM. Medication nebulizer performance. Effects of diluent volume, nebulizer flow, and nebulizer brand. Chest 1996;110(2):498-505.

6. Berlinski A, Willis JR. Albuterol delivery by 4 different nebulizers placed in 4 different positions in a pediatric ventilator in vitro model. Respir Care 2013;58(7):1124-1133.

7. Beaty CD, Ritz RH, Benson MS. Continuous in-line nebulizers complicate pressure support ventilation. Chest 1989;96(6): 1360-1363.
8. National Heart, Lung, and Blood Institute Acute Respiratory Distress Syndrome (ARDS) Clinical Trials Network, Matthay MA, Brower RG, Carson S, Douglas IS, Eisner M, et al. Randomized, placebo-controlled clinical trial of an aerosolized $\beta_{2-}$ agonist for treatment of acute lung injury. Am J Respir Crit Care Med 2011;184(5): 561-568.

9. Alzahrani W, Harwood R, Fink JB, Goodfellow L, Ari A. Comparison of albuterol delivery during high frequency oscillatory ventilation and conventional mechanical ventilation of a simulated adult. Respir Care 2010;55(11): 1576 .

10. Duarte AG. Inhaled bronchodilator administration during mechanical ventilation. Respir Care 2004;49(6):623-634. 